\title{
Near-infrared photonic energy penetration: can infrared phototherapy effectively reach the human brain?
}

\section{Theodore A Henderson ${ }^{1,2}$ Larry D Morries ${ }^{2}$}

'The Synaptic Space, Centennial, CO, USA; ${ }^{2}$ Neuro-Laser Foundation, Lakewood, CO, USA

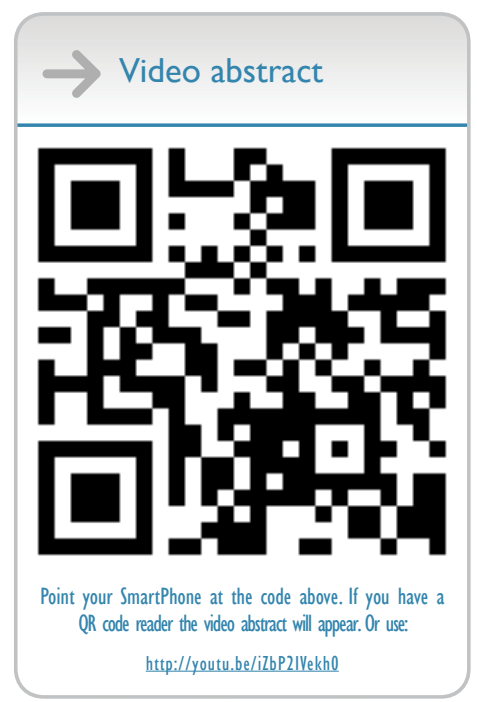

Correspondence: Theodore A Henderson

The Synaptic Space, 3979 E Arapahoe Road, Suite 200, Centennial, CO 80 II2, USA

Tel + I 720493 I I0I

Fax + I 720493 II 07

Email thesynapticspace7@gmail.com
This article was published in the following Dove Press journal:

Neuropsychiatric Disease and Treatment

2I August 2015

Number of times this article has been viewed

\begin{abstract}
Traumatic brain injury (TBI) is a growing health concern effecting civilians and military personnel. Research has yielded a better understanding of the pathophysiology of TBI, but effective treatments have not been forthcoming. Near-infrared light (NIR) has shown promise in animal models of both TBI and stroke. Yet, it remains unclear if sufficient photonic energy can be delivered to the human brain to yield a beneficial effect. This paper reviews the pathophysiology of TBI and elaborates the physiological effects of NIR in the context of this pathophysiology. Pertinent aspects of the physical properties of NIR, particularly in regards to its interactions with tissue, provide the background for understanding this critical issue of light penetration through tissue. Our recent tissue studies demonstrate no penetration of low level NIR energy through $2 \mathrm{~mm}$ of skin or $3 \mathrm{~cm}$ of skull and brain. However, at $10-15 \mathrm{~W}, 0.45 \%-2.90 \%$ of $810 \mathrm{~nm}$ light penetrated $3 \mathrm{~cm}$ of tissue. A $15 \mathrm{~W} 810 \mathrm{~nm}$ device (continuous or non-pulsed) NIR delivered $2.9 \%$ of the surface power density. Pulsing at $10 \mathrm{~Hz}$ reduced the dose of light delivered to the surface by $50 \%$, but $2.4 \%$ of the surface energy reached the depth of $3 \mathrm{~cm}$. Approximately $1.22 \%$ of the energy of $980 \mathrm{~nm}$ light at $10-15 \mathrm{~W}$ penetrated to $3 \mathrm{~cm}$. These data are reviewed in the context of the literature on low-power NIR penetration, wherein less than half of $1 \%$ of the surface energy could reach a depth of $1 \mathrm{~cm}$. NIR in the power range of 10-15 W at 810 and $980 \mathrm{~nm}$ can provide fluence within the range shown to be biologically beneficial at $3 \mathrm{~cm}$ depth. A companion paper reviews the clinical data on the treatment of patients with chronic TBI in the context of the current literature.
\end{abstract}

Keywords: infrared, traumatic brain injury, TBI, class IV laser, sleep disturbance, depression

\section{Introduction}

Traumatic brain injury (TBI) and stroke are major sources of morbidity and mortality worldwide. The World Health Organization has projected that TBI soon will be the third most frequent source of disability. ${ }^{1}$ Stroke is the second leading cause of death worldwide. ${ }^{2}$ While attention to the pathophysiologic processes that underlie neurotrauma has yielded considerable information, efficacious treatment strategies have yet to emerge. Treatment of neurological trauma is largely limited to mitigating the symptoms (see Morries and colleagues ${ }^{3}$ for review). Over the past decade, nearinfrared light (NIR) has gained attention as a potential treatment strategy for TBI and stroke in both the acute and chronic setting.

NIR has been investigated for its ability to modulate intracellular reparative mechanisms. NIR can facilitate wound healing ${ }^{4,5}$ and promote muscle repair ${ }^{5}$ and angiogenesis. ${ }^{4,5}$ The application of NIR by low power laser or by light emitting diode (LED), referred to as either laser phototherapy ${ }^{6}$ or near-infrared photobiomodulation, ${ }^{5}$ 
has been studied and applied clinically in a wide array of ailments, including skin ulcers, ${ }^{7}$ osteoarthritis, ${ }^{8}$ peripheral nerve injury, ${ }^{4,5}$ low back pain, ${ }^{9}$ myocardial infarction,,${ }^{10}$ and stem-cell induction. ${ }^{11}$ Since NIR passes relatively efficiently through bone, several studies of transcranial near-infrared light therapy (NILT) ${ }^{12}$ in animal models of brain damage have been conducted by multiple laboratories. A large clinical trial of NILT for acute stroke showed clinical improvement - NeuroThera Effectiveness and Safety Trial (NEST)-1;13 however, a subsequent Phase III clinical trial failed to show benefit at an interim futility analysis. ${ }^{14}$ This and other findings of ineffective protocols for NIR in a variety of pathological conditions ${ }^{15,16}$ raise an important question about the necessary elements of an effective therapy.

This review focuses on the relevant mechanisms of brain injury and NIR as it relates to the therapeutic use of NILT. To understand the ability of NILT to repair damaged or dysfunctional brain tissue resulting from stroke and TBI, it is first necessary to understand the relevant pathophysiological mechanisms of brain injury. Then the postulated mechanisms of NIR in mitigating these mechanisms will be reviewed. The physical properties of light and the manner in which it interacts with tissue are then elucidated. The ability of NIR to penetrate to sufficient depth with sufficient energy to exert a biological effect on the brain is key. Data on light penetration are provided and discussed in the context of the current literature on the topic.

\section{Pathophysiological mechanisms of neurotrauma}

TBI is a complex injury in which the nature of the sequelae depends on the region of the brain involved, injury severity, patient's age, and the nature and delay in initial care. TBI disrupts membrane function and gives rise to early ionic and neurotransmitter perturbations. ${ }^{17}$ Together with a substantial release of the excitatory neurotransmitter glutamate, these perturbations initiate a cascade of events that extensively disrupts normal cellular function, alters glucose metabolism, induces free radical production, and impairs mitochondrial function. ${ }^{17-20}$ An early event is increased release of potassium which is proportional to the severity of the injury. ${ }^{19}$ This has a robust inhibitory effect on neuronal activity. Calcium $\left(\mathrm{Ca}^{2+}\right)$ begins to accumulate within neurons and significantly impairs function. Increased intracellular $\mathrm{Ca}^{2+}$ activates mitochondrial uptake, leading to $\mathrm{Ca}^{2+}$ overload in mitochondria, ${ }^{17}$ oxidative stress, and impaired mitochondrial function. ${ }^{19-21}$ Accumulations of $\mathrm{Ca}^{2+}$ can directly destroy portions of the diverse mitochondrial population ${ }^{22}$ and induce persistent damage in surviving mitochondria ${ }^{23}$ (although, see Pandya et $\mathrm{al}^{24}$ ). Early excess glutamate can deplete metabolic pathways. Increased reactive oxygen and nitrogen species can indirectly deplete energy precursors and induce peroxidation of mitochondrial (and cellular) lipid membranes. ${ }^{20,25-27}$ The byproducts of lipid peroxidation have been implicated in inactivation or disruption of mitochondrial (and cellular) proteins. ${ }^{26}$ Mitochondrial DNA is particularly vulnerable to oxidative damage. As a result, all 37 mitochondrial DNA genes are disrupted, as well as 235 additional nuclear DNA genes. $^{28}$

Glucose is the primary energy source for neurons, but becomes considerably less available following TBI. Studies of cerebral glucose metabolism and fluorodeoxyglucose positron emission tomography have shown an initial brief increase in glucose metabolism, likely associated with glutamate flooding. ${ }^{18}$ Decreased glucose metabolism follows within 1 hour of injury and appears to be proportional to the severity of the injury. ${ }^{20,29}$ During the first 3-4 days, cerebral perfusion can be increased ${ }^{18}$ and a spreading depression of neuronal function and metabolism can occur. This is followed by a prolonged depression of both cerebral perfusion and cerebral glucose metabolism which has been shown in both humans ${ }^{30-32}$ and animal models. ${ }^{29,33}$ In addition, glucose transport from blood vessels is disrupted..$^{30}$ Moreover, glucose appears to be shunted from mitochondrial pathways to the pentose phosphate pathway. ${ }^{17-20,29}$ Overall these changes create an energy crisis inside the affected neurons.

This energy crisis promotes the increased concentration of free radicals, due to increased pentose phosphate metabolism, reduced mitochondrial function, and impaired free radical scavenger mechanisms. ${ }^{19}$ The consequences of increased free radicals can be far-reaching including propagation of additional free radicals, breakdown of lipids within membranes, ${ }^{34}$ edema, inflammation, and DNA damage. ${ }^{18,35}$

Neuroinflammation is an additional and incompletely understood mechanism in TBI. Recent evidence has shown that neural inflammation can persist for years following an injury. ${ }^{36-38}$ Using a positron emission tomography ligand for inflammation, one group demonstrated patients could have elevated inflammation 11 months to 17 years after a TBI. ${ }^{39}$ Notably though, areas of accumulated inflammation marker did not correspond to areas damaged directly by TBI. Altogether, these mechanisms appear to contribute to a progression in the size of the initial injury to involve surrounding areas (penumbra). ${ }^{36-38}$

In contrast to acute TBI, neurophysiological dysfunction in chronic TBI is less well understood. It is clear that 
mechanisms activated in acute $\mathrm{TBI},{ }^{18}$ such as neuronal injury and apoptosis, would have persistent consequences. Studies have shown that diffuse and Wallerian white matter degeneration occurs following TBI. ${ }^{40,41}$ In many ways, stroke and TBI share these long-term mechanisms. ${ }^{42,43}$ Long-term disruption of mitochondrial membranes by lipid peroxidation, disrupted $\mathrm{Ca}^{2+}$ regulation, loss of subpopulations of mitochondria, and reduced energy production can continue long past the acute phase of TBI. ${ }^{43}$ In humans, impaired mitochondrial function may persist for months to years based on observations of decreased glucose metabolism in patients using fluorodeoxyglucose positron emission tomography. ${ }^{31,44}$ Decreased cerebral blood flow to the injured area also persists for many years based on perfusion single photon emission computed tomography scans. ${ }^{32,45}$ Injured and disrupted axons, as well as altered proteolytic pathways in injured neurons, can lead to the accumulation of amyloid precursor proteins and tau proteins. ${ }^{46}$ Accumulations of these abnormal proteins can set in motion a sequence of pathophysiological processes leading to Alzheimer's disease, ${ }^{47,48}$ chronic traumatic encephalopathy, ${ }^{46,49}$ and Parkinson's disease. ${ }^{48,50,51}$ Blast injury may be particularly harmful, resulting in persistent axonal abnormalities of varicosities and accumulated abnormal proteins. ${ }^{52}$ Recent evidence has shown a strong correlation between persistent areas of disrupted white matter, shown by diffusion tensor imaging, and areas of decreased cerebral blood flow which were present at the time of injury. ${ }^{41}$ In the next section, the mechanisms by which NIR can potentially restore, repair, or mitigate the pathophysiological processes involved in TBI are elaborated. ${ }^{4,53-55}$

\section{Mechanisms of photobiomodulation Primary events}

The precise mechanisms underlying photobiomodulation and its therapeutic benefits are not fully understood. The purported effects of NIR are illustrated in Figure 1. Light in the wavelength range of 600-1,200 $\mathrm{nm}$ has significant photobiomodulation capability. ${ }^{56}$ Current data most strongly support that absorption of NIR photons by cytochrome $\mathrm{c}$ oxidase $(\mathrm{COX})$ in the mitochondrial respiratory chain is the key initiating event in photobiomodulation. ${ }^{4,54,56} \mathrm{COX}$ is a large transmembrane protein of the inner mitochondrial membrane. It contains two copper $(\mathrm{Cu})$ centers and two heme-iron centers. These metal centers have different light absorption peaks. Reduction of CuA occurs with $620 \mathrm{~nm}$, oxidation of $\mathrm{CuA}$ occurs with $825 \mathrm{~nm}$, reduction of $\mathrm{CuB}$ occurs with

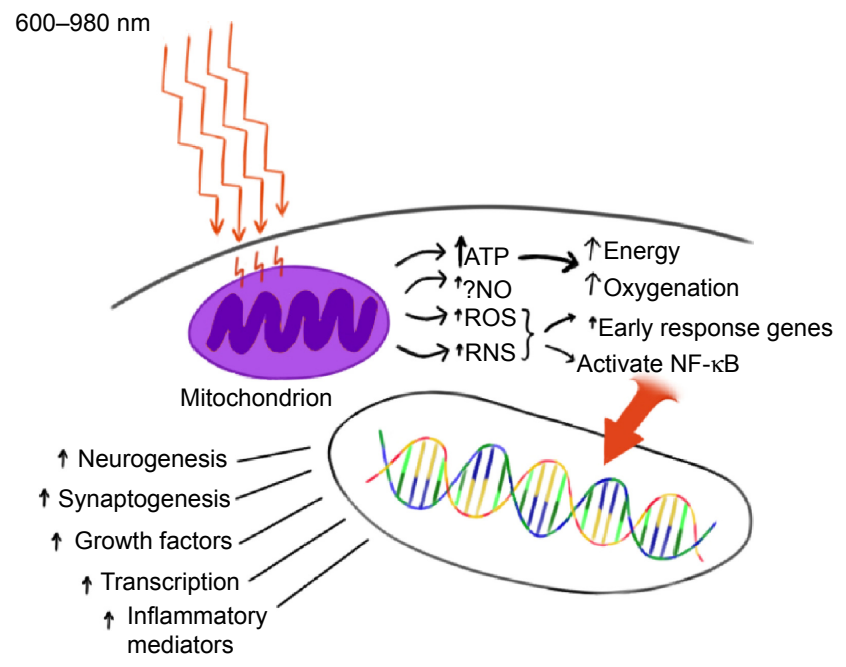

Figure I Hypothesized mechanism of action of near-infrared light (NIR) photobiomodulation.

Notes: NIR (600-980 $\mathrm{nm})$ penetrates tissue to variable depth depending on wavelength, coherence, time, and the tissue involved. A portion of the photonic energy reaches the mitochondria and is absorbed by cytochrome c oxidase. In addition to inducing increased adenosine triphosphate (ATP) production, NIR appears to initiate increased production of reactive oxygen species (ROS), reactive nitrogen species (RNS), and possibly (?) nitric oxide (NO). Downstream events include increased early response genes - $c$-fos, $c$-jun - and activation of nuclear factor kappa-B (NF-KB), which in turn induces increased transcription of gene products leading to neurogenesis, synaptogenesis, and increased production of growth factors and inflammatory mediators.

Abbreviation: $\uparrow$, increase.

$760 \mathrm{~nm}$, and oxidation of $\mathrm{CuB}$ occurs at $680 \mathrm{~nm} .{ }^{54}$ These peaks correspond to the "optical window" associated with the biological effects of NIR. Irradiation of COX increases the activity of the entire electron transport chain producing more adenosine triphosphate (ATP). In addition, COX is auto-inducible and its gene expression is activity dependent, such that NIR irradiation may increase the amount of available COX over time. ${ }^{57}$

NIR's effect has been studied in isolated mitochondria preparations. Irradiation with $632 \mathrm{~nm}$ light results in increased proton electrochemical potential and increased ATP production. ${ }^{58} \mathrm{COX}$ activity and oxygen consumption also increases. ${ }^{59}$ In a more recent study, Yu et $\mathrm{al}^{60}$ confirmed increased oxygen consumption and showed increased activation of several electron transport chain components. In the setting of acute neurotrauma, this increase in energy supply may be sufficient to reduce the consequences of injury. Neurons are often forced into anaerobic metabolism, which results in acidosis, insufficient energy to maintain ion pumps, and calcium overload. Later in the sequence of events following neurotrauma, more energy is required than at baseline due to the large energy requirements of repair. Increasing ATP during acute neurotrauma alone may be sufficient, but NIR appears to initiate a number of other events in the mitochondria. 


\section{Secondary events}

In addition to the increase in ATP, the change in redox state leads to greater oxidation and activation of the mitochondrial permeability transition pore which alters intermembrane potentials within the mitochondria. ${ }^{61}$ This may have a direct or indirect effect on gene transcription and protein synthesis. ${ }^{62}$ For example, transcription factors, such as redox factor1-dependent activator protein 1, activating transcription factor/cyclic adenosine monophosphate response element binding protein (ATF/CREB), and hypoxia-inducible factor alpha, are upregulated in response to changes in redox states. The change in redox state and NIR possibly directly ${ }^{63,64}$ result in the production of reactive oxygen species (ROS), the most common of which is superoxide. Similarly, NIR $(670 \mathrm{~nm})$ modulates the effects of reactive nitrogen species in a model of multiple sclerosis. ${ }^{65}$ ROS are potent second messenger molecules. ROS are involved in cell signaling, enzyme activation, nucleic acid synthesis, protein synthesis, and the activation of transcription factors.

The change in oxidation also likely contributes to the displacement of nitric oxide (NO) from the COX molecule. When bound, NO functions as an inhibitor by displacing oxygen from the binding site on COX. When NO is displaced, there is an increase in the activity of the electron transport chain. ${ }^{66}$ In addition, NO serves as a vasodilator and thus increases local blood flow. ${ }^{67} \mathrm{NO}$ also functions as a second messenger. Numerous tissue culture and animal studies have demonstrated the effect of NIR on NO levels, ${ }^{4,68,69}$ including the upregulation of NO synthase expression. $^{70}$

Nuclear factor kappa-B (NF- $\mathrm{kB})$ is a redox sensitive transcription factor. ${ }^{71}$ This pro-survival transcription factor modulates the expression of numerous genes, including ones involved in inflammation, early response (heat shock), anti-apoptosis, cellular migration, and cell survival. ${ }^{71,72}$ NIR $(810 \mathrm{~nm})$ activates NF- $\mathrm{\kappa B}$ apparently via ROS in cultured fibroblasts. ${ }^{72} \mathrm{NF}-\kappa \mathrm{B}$ can be activated by ROS and indirectly by the effects of ROS on inflammatory cytokines (eg, tumor necrosis factor, interleukin-1). ${ }^{73}$

\section{Tertiary events}

With NIR exposure, induction of mitochondrial RNA synthesis,${ }^{74}$ as well as protein synthesis, occurs. ${ }^{75}$ More recent work has shown NIR induces the upregulation and downregulation of numerous genes both in the nucleus and in the mitochondria of various cell types. Kushibiki et $\mathrm{al}^{76}$ have reviewed the mitochondrial RNA expression changes associated with photobiomodulation. Zhang et al ${ }^{17}$ demonstrated changes in mRNA expression of over 100 genes in cultured fibroblasts exposed to $653 \mathrm{~nm}$ NIR. Genes involved in cell proliferation, such as mitogen-activated protein kinase 11 (MAPk11), and cell-cycle progression are increased..$^{77}$ Apoptosis-inhibiting genes are upregulated (eg, Janus kinase binding protein). Meanwhile, apoptosispromoting genes, such as heat shock $70 \mathrm{k}$ Da protein $1 \mathrm{~A}$ and caspase 6, are downregulated. ${ }^{77}$ Expression of genes for antioxidants and inhibitors of the effects of ROS are increased. Similar work in the retina has shown that genes involved in cell survival, antioxidant production, transcription, and growth factor production are also upregulated in neural retina cells. ${ }^{78}$

Data from tissue culture and animal studies of NIR reveal an increase in growth factor expression ${ }^{68,72,79,80}$ and subsequent cell proliferation. ${ }^{4,12,68,69}$ Examples of these key growth factors include nerve growth factor, brain-derived neurotrophic factor, transforming growth factor-beta, and vascular endothelial growth factor, which may contribute to late brain remodeling after TBI. . $12,54,68,73,79-86$ For example, a fivefold increase in nerve growth factor mRNA transcription occurred after irradiation of skeletal muscle cell culture with $633 \mathrm{~nm}$ NIR light. ${ }^{85}$

Recent data suggest that transcranial NIR phototherapy can increase the process of neurogenesis in adult mice with stroke or TBI. Increased numbers of neuroprogenitor cells have been demonstrated in both the dentate gyrus of the hippocampus and in the subventricular zone of the lateral ventricle of mouse models. ${ }^{4,87,88}$ These cells also demonstrate increased expression of a microtubule protein associated with migrating neuroblasts. ${ }^{88}$ Some studies provide evidence that NIR phototherapy may increase the process of synaptogenesis. ${ }^{488}$ Together, these processes may aid in the neuroplasticity responsible for neural repair and improved function in cases of chronic TBI.

These cellular changes appear to persist for considerably longer than the interval of light application ${ }^{89}$ (when delivered at appropriate wavelengths and amplitudes). ${ }^{4}$ For example, low level (red and) near-infrared light therapy (LLLT) of a power density of $0.9-36 \mathrm{~J} / \mathrm{cm}^{2}$ applied in a single treatment at 24 hours post-stroke in animal models yielded a reduction in neurological deficits, as well as histochemical evidence of neuron proliferation and migration. . $5,88,90,91^{2}$ A single application of LLLT in rodent models of TBI had similar benefits. ${ }^{487,92-94}$ Interestingly, these benefits were not immediately apparent. Rather, a delay of 1-4 weeks was noted, consistent with a progressive regeneration cascade set in motion by the NIR exposure. 


\section{Summary}

During NIR phototherapy, absorption of red or NIR photons by $\mathrm{COX}$ in the mitochondrial respiratory chain causes secondary molecular and cellular events, including activation of second messenger pathways, changes in NO levels, and growth factor production. NILT leads to the reduction of excitotoxicity, the production of neurotrophic factors, the modulation of ROS, the transcription of new gene products with protective or pro-proliferative properties, and the release of numerous growth factors for neurons and other cells. ${ }^{4,64,68,73,82-84}$ NIR appears to initiate a cascade of subcellular events which can yield immediate, delayed, and persistent beneficial changes in the injured neuron or other cell.

\section{Properties of NIR}

Light has fundamental physical properties which are relevant to its clinical use. Light is a form of electromagnetic radiation which has properties of both waves and particles. Light is characterized by its wavelength (distance between two peaks), frequency, and amplitude. Light is also characterized by its energy content. This energy is quantified as joules (J). The amount of energy delivered per unit time constitutes the power of light in watts ( $\mathrm{W}=\mathrm{J} / \mathrm{second})$. For medical applications, light is typically reported in terms of wavelength (nm), energy $(\mathrm{J})$, irradiance or power density $\left(\mathrm{W} / \mathrm{cm}^{2}\right)$, and radiant exposure or fluence or dose $\left(\mathrm{J} / \mathrm{cm}^{2}\right) .^{54,95}$

NIR has a number of biological effects, but it is critical to understand the physical interactions between tissue and light. When light impinges on the surface, a portion $(\sim 10 \%)$ is reflected ${ }^{96}$ The energy that does penetrate the surface is refracted or bent toward a line perpendicular to the surface. This results from the particle property of light. These particles are, of course, photons. The photons entering the tissue can be transmitted through the tissue, scattered, or absorbed. Scatter increases the volume of tissue impacted by the light. Photons can change direction without loss of energy. Scattering is particularly likely at interfaces between different tissues. Reflection or refraction also occurs at such interfaces. These effects contribute to shortening the distance to which light will travel or penetrate into the tissue. ${ }^{96-98}$

Most tissues have the capacity to absorb light energy. Usually this is mediated by a molecule absorbing a photon. Molecules containing metal ions have a strong capacity for absorbing photonic energy, but DNA and water also can. The absorption of energy can induce a change in the confirmation and/or function of the molecule.

Penetration of NIR through tissues is determined by several factors: wavelength, energy, attenuation coefficient (composed of scatter, refraction, and absorption), area of irradiance, coherence, and pulsing. In general, longer wavelengths (up to 1,000 nm) will penetrate deeper; however, the absorption of water begins to predominate above $1,000 \mathrm{~nm} .{ }^{96}$ Increases in power density, in general, will lead to greater penetration. More photons will traverse the tissue. The area of surface irradiation also affects penetration due to scattering effects.

Coherence is a property of light waves in which waves of monochromatic light are aligned such that any point on the wave has the same amplitude and position as the equivalent point in an adjacent wave. Temporal coherence reflects the slight variations in the waveform over time. The more consistent the waveform is, the higher the temporal coherence. Monochromatic light typically has high temporal coherence. Spatial coherence results from the divergence of the light from the point of emission. ${ }^{66}$ Laser has virtually no spatial divergence and creates a long narrow volume of coherent light. LEDs are not monochromatic, but emit light in a relatively narrow band over the peak wavelength. LEDs also have significant spatial divergence and therefore a wide volume of space is radiated; however, within that volume only a very small volume contains coherent light. As Karu ${ }^{66}$ illustrates, the result is that noncoherent LED sources likely only provide coherent light in a thin volume, usually at surfaces. In contrast, laser generates a long narrow volume of coherent light which can penetrate deeper into tissues.

When coherent light enters a tissue, slight distortions in the timing and the shape of the waves occur. As a result, interference can occur between the waves. Polarization, the angle at which a wave is vibrating, also contributes to interference. On a single wave basis, interference results when the amplitude of the wave at a given point is different from that of an adjacent wave and of the population of coherent light waves. At the point of difference, the amplitudes can either cancel each other out $\{[+\mathrm{x}]+[-\mathrm{x}]\}$, be additive $\{[+\mathrm{x}]+[+\mathrm{x}]\}$, or any variation in between $\{[+\mathrm{x}]+[-\mathrm{y}]\}$. The result of these interactions is a field of randomly distributed points of increased and decreased light intensity, referred to as a speckle intensity pattern. Speckling can have a significant impact on the effective penetration depth. ${ }^{99}$ As such, areas of high intensity will penetrate further or will have two to three orders of magnitude greater energy at a given depth. ${ }^{99}$

Pulsing of NIR also increases the depth of penetration and the amount of energy delivered to any given point at the peak of a pulse. Yet, pulsing allows for troughs of energy 
output such that the overall energy delivered to the tissue can be equivalent or even lower than that delivered by a continuous emission. Pulsing is a property of lasers which cannot be duplicated by LEDs.

\section{Limitations of NILT protocols}

Prior clinical applications of NIR photomodulation have utilized LLLT emitters and prolonged courses of daily treatments often extending over months. ${ }^{100,101}$ For example, the first published study of NIR therapy for TBI in humans described two cases of chronic mild TBI with significant disability. ${ }^{100}$ Each patient had marked neuropsychological improvement after a prolonged series of LLLT treatments using 870 and $633 \mathrm{~nm}$ LED arrays over 4-72 months. Yet, some clinical and laboratory studies of LLLT have failed to consistently demonstrate benefit. ${ }^{15,16,102,103}$ For example, Lavery et $\mathrm{l}^{15}$ demonstrated that LLLT (890 nm LEDs delivering $1.3 \mathrm{~J} / \mathrm{cm}^{2}$ for 40 minutes daily for 90 days) did not yield significant improvement in nerve conduction velocity in patients with diabetic neuropathy. Similarly, treatment of a rat model of contusive spinal cord injury with LLLT $\left(830 \mathrm{~nm}\right.$ at $22.6 \mathrm{~J} / \mathrm{cm}^{2}$ or $670 \mathrm{~nm}$ at $28.4 \mathrm{~J} / \mathrm{cm}^{2}$ ) for 30 minutes per day for 5 days resulted in no significant functional improvement and no reduction in lesion size. ${ }^{16}$ The identical treatment regimen was applied to a rat model of TBI with no detectable improvement in motor or sensory function or change in lesion size. ${ }^{16}$ In this animal model, Giacci et al calculated $2.6 \mathrm{~J} / \mathrm{cm}^{2}$ reached the spinal cord with each treatment. This is within the range of reported beneficial doses; yet, it was not effective. Note that several studies have shown that LLLT radiant energy is almost completely absorbed in the first $1 \mathrm{~mm}$ of skin. ${ }^{104,105}$

A clinical example of this discrepancy has unfolded in the clinical trials for the treatment of stroke utilized in the NEST-1 and NEST-2 trials. ${ }^{106,107}$ Lapchak $^{12}$ reported that the physical parameters of NILT in these studies may have delivered insufficient energy to cortical tissues to be effective. Therein, $808 \mathrm{~nm}$ NIR with energy densities of $0.9 \mathrm{~J} / \mathrm{cm}^{2}$ was applied to the human scalp at multiple sites for a total of 40 minutes. ${ }^{106,107}$ Note that animal models of both stroke and TBI indicate NIR energy densities in the range of $0.9-36 \mathrm{~J} / \mathrm{cm}^{2}$ yields significant biochemical and behavioral changes. ${ }^{3,4,81,87-90,93,94}$ The concern raised from the NEST studies $^{12}$ is that current clinical trials using LLLT to treat TBI may yield negative or inaccurate efficacy data, not because of the incapacity of NIR to invoke a change, but due to a dose error. Doses that are effective when directly applied to a monolayer of cells ${ }^{75,82}$ or when penetrating $0.2 \mathrm{~mm}$ through the skull of a rodent ${ }^{108}$ and the $5 \mathrm{~mm}$ through the full thickness of the mouse brain, ${ }^{4,81,87,88,92-94,109}$ may be insufficient to penetrate to $20-30 \mathrm{~mm}$ into the human brain.

We have been utilizing relatively high power $(10-15 \mathrm{~W})$ lasers at the wavelengths of 810 and $980 \mathrm{~nm}$ in clinic to treat TBI with positive results. ${ }^{3}$ The use of NIR in the treatment of stroke and of TBI are reviewed in a companion paper. ${ }^{3}$ Skin is the first tissue encountered in the clinical application of NIR phototherapy and represents a barrier to effective penetration due to several factors. Human skin has multiple layers and, therefore, multiple interfaces. Each interface is a surface for scatter. In addition, each layer has different inherent optical properties. ${ }^{97,110}$ The epidermis, comprised in part of keratin, collagen, lipids, and melanin, has high absorption in the ultraviolet range, but also absorbs light in the infrared range of $600-1,100 \mathrm{~nm} .{ }^{110}$ The dermis, comprised in part of collagen, elastin, and proteoglycans, is of variable thickness and penetration varies as a result. Scattering is a predominate property of the dermis. ${ }^{110}$ The dermis is also dense with blood vessels and the hemoglobin-rich blood therein. While hemoglobin has absorption peaks at 450 , 550 , and $600 \mathrm{~nm},{ }^{97}$ it also absorbs photonic energy in the clinical NIR range of $800-1,100 \mathrm{~nm} \cdot{ }^{110,111}$ The NIR absorption of hemoglobin depends upon its oxygenation status, with carboxyhemoglobin having greater NIR absorption. ${ }^{11}$ Altogether, NIR photonic energy must first overcome the hurdle of penetrating the skin to have an impact on deeper structures.

We have shown clinical improvement in patients with TBI utilizing high power NIR sources, but does high power NIR penetrate deeper and/or with greater fluence compared to LLLT? We have explored NIR penetration of tissues of clinical relevance or previously modeled to quantify the effective penetration at power densities ranging from the 50-200 $\mathrm{mW}$ levels used in LLLT ${ }^{87,88,90-94}$ to high power levels used in clinical studies of TBI treatment. ${ }^{3}$ Specifically, NIR in the wavelengths often used in clinical studies of red and NIR photobiomodulation were utilized $\left(650-670 ;{ }^{16,100}\right.$ $\left.810 ; 87,93,94880 ; ;^{100} 980 \mathrm{~nm}^{112,113}\right)$. Power levels ranged from 50 to $200 \mathrm{~mW}$ to model LLLT and from 6 to $15 \mathrm{~W}$ to model high power NIR phototherapy. Specific tissues included sheep skin and human skin to model skin penetration based on issues raised in studies by Kolari and Airaksinen, ${ }^{114}$ Bjordal et al, ${ }^{8}$ and Esnouf et al. ${ }^{104}$ Sheep head, with skin, skull, and brain intact, served as a model of human brain penetration. ${ }^{3}$ 


\section{Recent findings concerning NIR attenuation \\ Ethical considerations}

Animal tissue was obtained from local slaughter facilities and no animals were sacrificed exclusively for these experiments. Human tissue was obtained from ScienceCare (Denver, CO, USA), a commercial agency which adheres to all federal and state legal requirements through the Uniform Anatomical Gift Act, and is accredited by the American Association of Tissue Banks. All guidelines for the ethical handling and disposal of human tissue were adhered to strictly. Ethics approval was not sought for the in vivo human tissue studies, because the authors themselves served as the subjects of the tissue experiments. Verbal informed consent was exchanged between the authors in the planning and preparation of these in vivo human tissue studies.

\section{Ex vivo tissue studies}

Sheep skin

Lamb heads were obtained within 12 hours of slaughter. Areas of skin were shaved and sections approximately $3 \times 3 \mathrm{~cm}$ were excised. The thickness of the skin was measured with precision calipers. A recently calibrated light meter (Ophir-Spiricon LLC, North Logan, UT, USA) was positioned in a custom-made holder with a calibrated carriage to hold an NIR emitter at a fixed and measurable distance from the surface of the light meter. Several different NIR emitters were utilized in this phase of the study to explore the effects of frequency, power density, pulsing, and LED versus laser on the penetration of NIR. Each emitter was positioned in the carriage of the meter holder and set a fixed distance from the meter surface. The baseline light transmission through air at that distance was determined by five separate measurements. The skin sample was then interposed and NIR transmission through the skin sample was measured over five separate trials each lasting 10 seconds. Temperature readings were obtained using a laser digital sensor (Cen-Tec, Kunshan City, People's Republic of China) from the surface facing the NIR emitter and the surface facing the light meter after each transmission trial. This procedure was repeated for all NIR emitters studied.

A $50 \mathrm{~mW}$ LED emitter at $810 \pm 20 \mathrm{~nm}$ was constructed to emulate commercially available NIR diode devices which are arranged in arrays and utilized in other studies of LLLT for the treatment of the human brain. This LED was constructed by arranging commercially available diodes in a concave metal faceplate to emit $50.4 \pm 5.0 \mathrm{~mW}$. This custom device is referred to herein as "Custom LED". Five commercially available NIR emitters were also evaluated. The In Light pad (In Light Wellness System, Albuquerque, NM, USA) has an array of LEDs emitting 650 and $880 \mathrm{~nm}$ light at $200 \mathrm{~mW}$. The Eltech K-Laser 6D is a $6 \mathrm{~W}$ emitter (Eltech Srl, Treviso, Italy) with dual wavelengths of 670/970 nm. The LiteCure LT1000 (LiteCure LLC, Newark, DE, USA) is a $10 \mathrm{~W}$ adjustable laser NIR emitter with a dual wavelength of $810 / 980 \mathrm{~nm}$ and can be set to continuous or pulsed light emission. The Diowave $810 \mathrm{~nm}$ laser (Technological Medical Advancements, Inc, West Palm Beach, FL, USA) is adjustable up to $15 \mathrm{~W}$, has a wavelength of $810 \mathrm{~nm}$, and can deliver continuous or pulsed NIR. The Diowave $980 \mathrm{~nm}$ laser (Technological Medical Advancements, Inc) also is adjustable up to $15 \mathrm{~W}$ and can deliver continuous or pulsed NIR.

\section{Penetration of sheep skin}

Ex vivo studies of NIR penetration through fresh lamb skin revealed a marked decrease in power density through a skin thickness of only $2 \mathrm{~mm}$ (Table 1). The Custom $50 \mathrm{~mW}$ $810 \mathrm{~nm}$ LED did not appear to penetrate $2 \mathrm{~mm}$ of skin. Similarly, the commercial $0.2 \mathrm{~W} 650 / 800 \mathrm{~nm}$ LED system (In Light) did not show any detectable energy penetrating the $2 \mathrm{~mm}$ of sheep skin. When compared to the power density of penetration through $2 \mathrm{~mm}$ of air, the $6 \mathrm{~W}$ LED of wavelength $670 / 970 \mathrm{~nm}$ had an approximately 12\%-20\% penetration, predominately in the red light range of $670 \mathrm{~nm}$. The $10 \mathrm{~W}$ combined 810/980 $\mathrm{nm}$ infrared laser (LiteCure) showed a power density drop of $91 \%$ across $2 \mathrm{~mm}$ of skin. The $15 \mathrm{~W} 810 \mathrm{~nm}$ laser (Diowave) demonstrated a 67\% drop in power density, while the $15 \mathrm{~W} 980 \mathrm{~nm}$ laser (Diowave) demonstrated an $86 \%$ drop in power density across the same thickness of skin. All of these levels of penetration were statistically significant compared to the LED systems.

Using pulsed infrared light yielded much greater penetration. For example, $13.8 \%$ of the power density of a combined $810 / 980 \mathrm{~nm}$ infrared laser with a pulse frequency of $10 \mathrm{~Hz}$ penetrated $2 \mathrm{~mm}$ of skin compared to only $8.6 \%$ of the continuous wave light of similar parameters. The $15 \mathrm{~W} 810 \mathrm{~nm}$ laser with a pulse frequency of $10 \mathrm{~Hz}$ had a power density drop of $66 \%$ across $2 \mathrm{~mm}$ of skin. The $15 \mathrm{~W} 980 \mathrm{~nm}$ infrared laser with a pulse frequency of $10 \mathrm{~Hz}$ had only a $39 \%$ drop in power density across a similar skin thickness. This difference was not statistically significant with multiple comparisons, but a trend was evident.

One concern about higher-powered infrared light sources is the risk of tissue heating. Here, we observed the low power LEDs made no significant temperature change in the skin samples. The $10 \mathrm{~W}$ combined $810 / 980 \mathrm{~nm}$ and the 


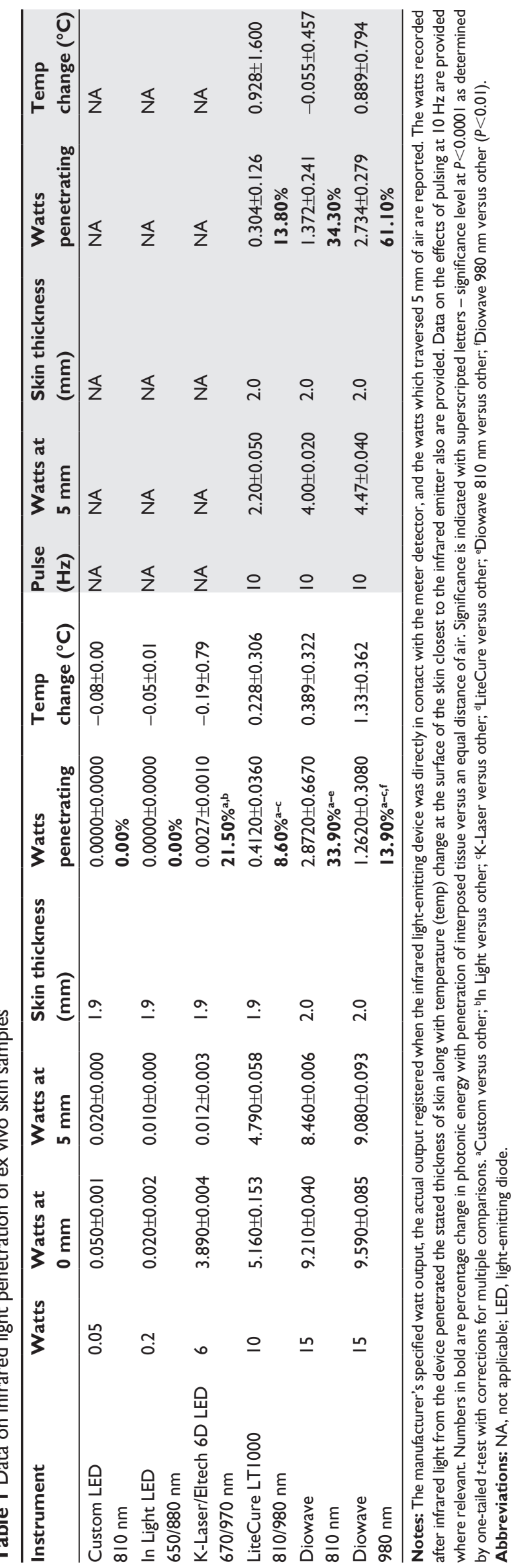

$15 \mathrm{~W} 810 \mathrm{~nm}$ infrared lasers made no significant temperature change when keeping the emitter head in motion. Temperature increase with the $15 \mathrm{~W} 980 \mathrm{~nm}$ infrared laser was $1.33^{\circ} \mathrm{C}$. Notably, temperature change using $10 \mathrm{~Hz}$ pulsing was not significant.

Animal skin serves as a useful model for human skin but differs from human skin in many ways. The density of hair follicles and melanin in the epidermis represent important differences which could be predicted to impact NIR penetration. We also studied NIR penetration in human skin samples obtained from a tissue bank.

\section{Ex vivo human skin studies}

The same protocol was used to measure light transmission through human skin. A full-thickness section of human skin measuring $15 \times 15 \mathrm{~cm}$ square was prepared by removing all subcutaneous fat by dissection and isolating separate segments measuring $7 \times 7 \mathrm{~cm}$. The thickness of the human skin was measured with digital calipers. Different NIR emitters were again utilized. Each emitter was positioned in the carriage of the meter holder and set a fixed distance from the meter surface. The baseline light transmission through air at that distance was determined by five separate measurements. The skin sample was then interposed and light transmission through the skin sample was measured over five separate trials each lasting 10 seconds. As shown in Figure 2, LEDs were positioned against the skin sample with an intervening sheet of clear plastic wrap. Temperature readings were obtained using the laser digital sensor from the surface facing the NIR emitter after each transmission trial. This procedure was repeated for all NIR emitters studied.

\section{Penetration of human skin}

Ex vivo human skin was utilized to study transmission of NIR photonic energy (Table 2, Figure 2). The Custom $0.05 \mathrm{~W} 810 \mathrm{~nm}$ LED did not appear to penetrate $1.9 \mathrm{~mm}$ of human skin. The commercial $0.2 \mathrm{~W} 650 / 880 \mathrm{~nm}$ In Light LED system delivered $0.01 \pm 0.002 \mathrm{~W}$ across $2 \mathrm{~mm}$ of air. No energy could be detected penetrating the $1.9 \mathrm{~mm}$ thickness of human skin with this device. Energy from the $10 \mathrm{~W}$ combined 810/980 nm infrared laser could be detected penetrating $1.9 \mathrm{~mm}$ of human skin and a power density drop of $89 \%$ across $1.9 \mathrm{~mm}$ of human skin was noted with $0.994 \mathrm{~W}$ penetrating the tissue. The $15 \mathrm{~W} 810 \mathrm{~nm}$ laser demonstrated an $83 \%$ drop in power density across a similar thickness of human skin with $2.008 \mathrm{~W}$ penetrating the tissue. The $15 \mathrm{~W}$ $980 \mathrm{~nm}$ laser was not tested on human skin. Photonic energy penetration of the two laser devices was statistically different 

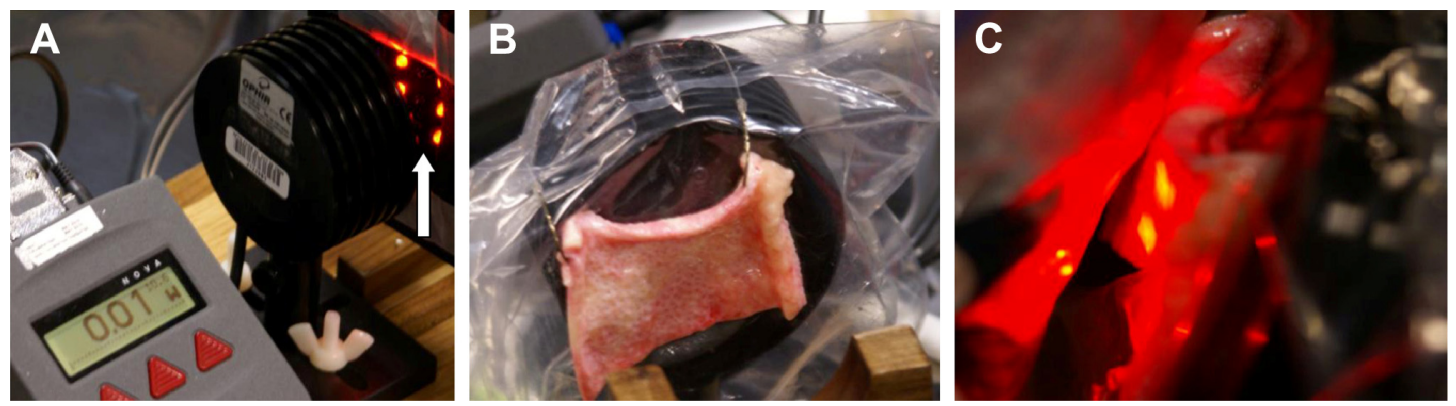

Figure 2 Ex vivo human skin studies illustrated.

Notes: (A) The pad of LEDs is held $2 \mathrm{~mm}$ from the surface of the light meter detector. The arrow indicates a row of near-infrared light (NIR) LEDs with a wavelength of $880 \mathrm{~nm}$. The meter reads $0.01 \mathrm{~W}$. (B) Human skin $1.9 \mathrm{~mm}$ thick is interposed between the NIR LED and the light meter detector. Thin plastic wrap covers the detector. (C) The NIR LED is covered with thin plastic wrap and placed directly against the sample of human skin. Photonic energy could not be detected passing through I.9 mm of human skin.

from that of any LED device (which showed no photonic energy transmission through human skin). Penetration of human skin also was statistically different between the two laser devices $(P<0.000005)$.

For NIR to penetrate to the brain and impact neurological injury (stroke or TBI) or disease, it must be able to reach the depths of the brain with sufficient fluence to trigger molecular events. ${ }^{3}$ It is not sufficient to reach the cortical surface, as neurological disease involves areas beyond the cortical surface. Indeed, NIR photonic energy may need to reach depths of 3-7 cm. For example, TBI most frequently involves the ventral surface of the frontal lobe, and the anterior and medial temporal lobes. ${ }^{32}$ Parkinson's disease involves the substantia nigra and the striatum, both located 4-7 $\mathrm{cm}$ from the surface of the scalp. Stroke can often involve the cortical surface, but also impact deeper structures of the brain. In fact, this issue of penetration may have been at the root of the failure of NEST-3 $3^{13,106,115}$ concerning the clinical efficacy of NIR phototherapy for stroke. In that trial, the inclusion criteria concerning stroke locations were broadened to include strokes with deeper areas of involvement. ${ }^{3}$

\section{Skull and brain}

Lamb heads were obtained within 12 hours of slaughter. Lamb heads were bisected with a coronal cut (ear to ear) and the portion of parietal and occipital skull and skin with underlying brain were utilized for NIR transmission studies. The same protocol was used to measure light transmission through the skull, overlying tissue, underlying tissue, and brain tissue of lamb heads. The distance of the linear trajectory though the partial lamb head was measured with digital calipers. The carriage of the meter holder was adjusted to allow sufficient clearance to interpose the large piece of tissue between the NIR emitter and the meter. The baseline light transmission through air at that distance was determined by five separate measurements. As shown in Figure 3, the head sample was then interposed with the skull facing the NIR emitter and the exposed cut surface of brain in contact with the light meter. Light transmission through the sample was measured over five separate trials each lasting 10 seconds. Temperature readings were obtained with a laser digital sensor from the skin surface facing the NIR emitter and the brain surface facing the light meter after each transmission trial. This procedure was repeated for all NIR emitters studied, including the Custom 0.05 W LED device and five commercially available NIR emitters (the In Light 650 and $880 \mathrm{~nm}$ emitter, the Eltech K-Laser 6D 6W 670/980 nm emitter, the LiteCure LT1000 $10 \mathrm{~W}$ adjustable laser NIR emitter with a dual wavelength of $810 / 980 \mathrm{~nm}$, the Diowave laser adjustable up to $15 \mathrm{~W}$ with a wavelength of $810 \mathrm{~nm}$, and the Diowave $980 \mathrm{~nm}$ laser adjustable up to $15 \mathrm{~W}$ ).

\section{Penetration $3 \mathrm{~cm}$ into brain}

Ex vivo studies of NIR penetration through $3 \mathrm{~cm}$ of lamb skull, tissue, and brain in a segmented head revealed a profound decrease in power density which was related to wavelength and wattage (Table 3, Figure 3). The Custom $0.05 \mathrm{~W}$ LED did not penetrate $3 \mathrm{~cm}$ through either air or brain tissue. No detectible energy from the $0.2 \mathrm{~W} 650 / 880$ (In Light) LED system could be detected at $3 \mathrm{~cm}$ through air or tissue. The 6 W LED (Eltech K-Laser 6D) showed a $99.995 \%$ drop in power density across $3 \mathrm{~cm}$ of tissue. When compared to the power density of penetration through $3 \mathrm{~cm}$ of air, the $10 \mathrm{~W} \mathrm{810/980} \mathrm{nm} \mathrm{(LiteCure)} \mathrm{device} \mathrm{showed} \mathrm{a}$ $99.65 \%$ drop in power density across $3 \mathrm{~cm}$ of skin, skull, and brain tissue. The $15 \mathrm{~W} 810 \mathrm{~nm}$ (Diowave) device in continuous (non-pulsed) NIR delivered $2.9 \%$ of the surface power density, while only $1.22 \%$ of the surface power density at $980 \mathrm{~nm}$ reached the $3 \mathrm{~cm}$ depth through brain tissue indicating that wavelength is indeed an important parameter in reaching deep tissues. Photonic energy penetration with 


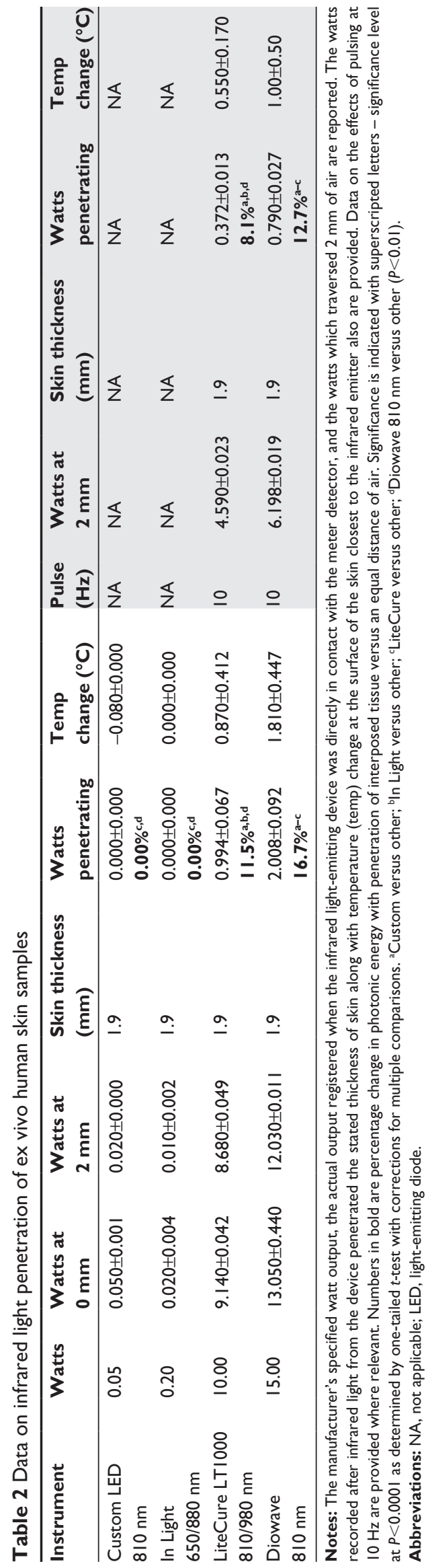

the laser devices was statistically different from the LED devices; however at this depth, the laser devices did not differ significantly from each other using continuous NIR delivery. Using pulsed NIR emission settings, lower total fluency and heat is delivered to the skin surface, while energy delivered to deeper structures at a pulse peak is greater. Pulsed energy penetration to $3 \mathrm{~cm}$ was significantly different between the three laser devices $(P<0.01)$.

Temperature changes at the skull surface ranged from $0.2^{\circ} \mathrm{C}$ to $3^{\circ} \mathrm{C}$. Temperature change in the brain was less than $1^{\circ} \mathrm{C}$ except when using the $980 \mathrm{~nm} 15 \mathrm{~W}$ laser in continuous emission setting. In the latter case, the temperature variation was quite large. These data show less temperature change using the pulsed setting regardless of wavelength and power.

NIR transmission through living tissue is likely different than through postmortem tissue for a number of reasons. First, cross-linking of proteins is an early and progressive event in death. Second, changes in interstitial fluids occur within hours of death. Third, the perfusion of dermis and deeper tissues in vivo creates scatter and refraction of NIR. Fourth, the flow of blood also disperses heat from the site of NIR application. Lastly, some authors have suggested that NO created at the site of irradiation and carried throughout the body in the blood is responsible for the beneficial effects of NIR phototherapy. ${ }^{116}$ This effect could account for the clinical benefits seen in TBI if NIR does not penetrate to the depths of $3 \mathrm{~cm}$ or greater in living tissue. Jagdeo et al modeled NIR penetration in living human tissue by serving as their own author/volunteers. ${ }^{117}$ We have replicated some of their work using a higher-powered NIR source. Tissues included hand, cheek, ear, and triceps to model the complex mixture of skin, bone, connective tissues, and other tissues found in the pathway of NIR en route to the brain.

\section{In vivo human tissue studies}

The in vivo penetration of NIR through human tissue was measured compared to NIR penetration of air. The Diowave $810 \mathrm{~nm}$ high power laser was the only NIR emitter utilized in this portion of the study. The power output was set at 13.5 $\mathrm{W}$ for a duration of 5 seconds. First, the thickness of two different human hands was measured with digital calipers. The passage of NIR through 25 or $30 \mathrm{~mm}$ of air was repeatedly measured (Table 3 ). Then, the passage of NIR across the equivalent distance of the palm of a human hand was repeatedly measured. Intervening anatomical structures included skin, tendon, bone, muscle, blood, and connective 

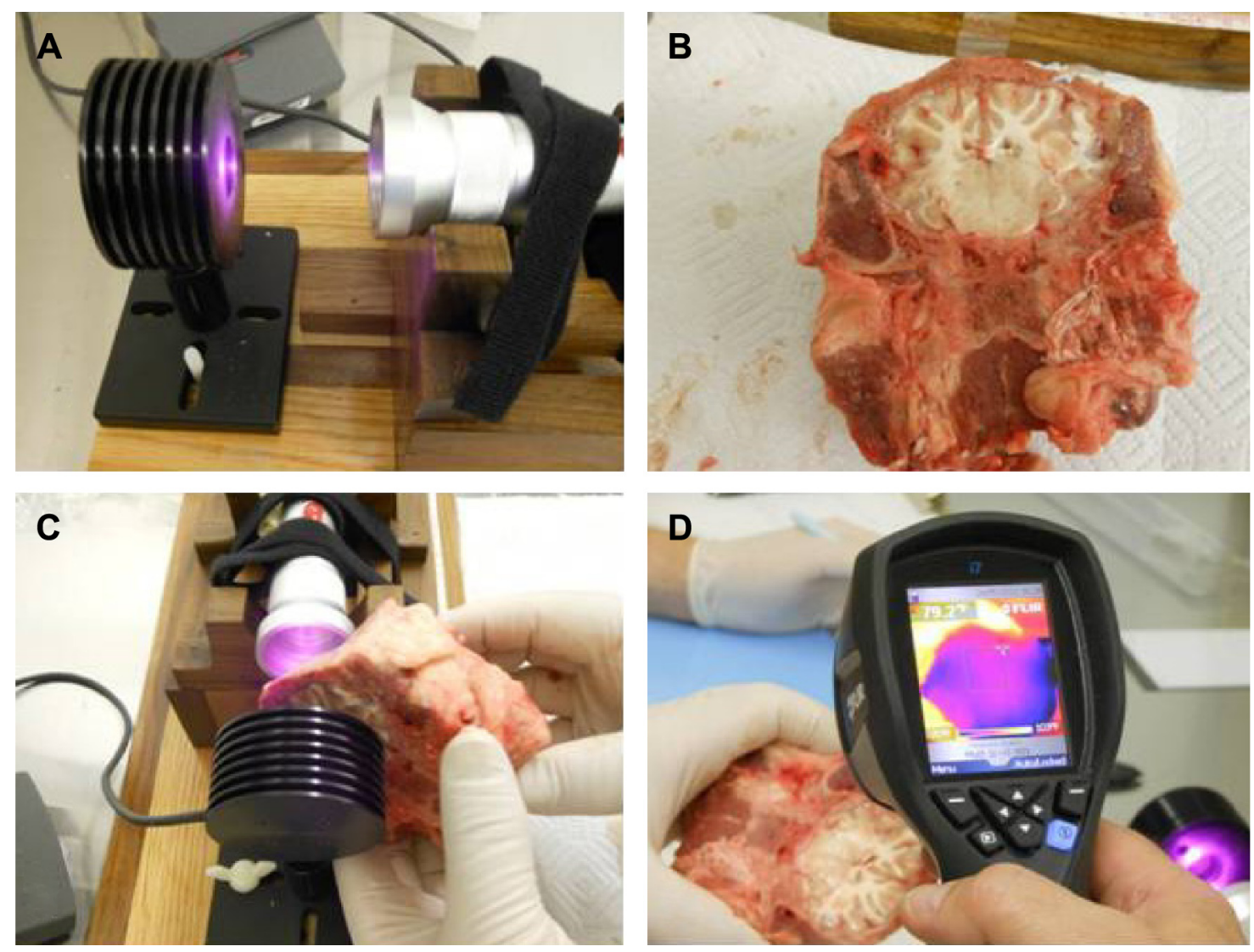

Figure 3 Ex vivo brain tissue studies illustrated.

Notes: (A) The photonic energy penetrating a fixed distance $(3 \mathrm{~cm})$ of air was determined. (B) A section of ex vivo lamb head was prepared which included skull, tissue, and brain. (C) The section was interposed in the space between the infrared light emitter and the light meter detector, both of which were fixed in place. The amount of infrared light energy penetrating the fixed distance $(3 \mathrm{~cm})$ through tissue was determined. (D) The temperature change was determined using a digital thermometer before and immediately after infrared light exposure.

tissue. In a similar fashion, the thickness of subcutaneous tissue at the level of the triceps muscle was measured with digital calipers. The penetration of NIR through skin, blood, and muscle was compared to NIR penetration through the equivalent distance $(20 \mathrm{~mm})$ of air. Measurements were collected on three separate trials.

The penetration of NIR through the $9 \mathrm{~mm}$ thickness of human cheek was determined by enclosing the laser light emitter in cellophane and inserting the light emitter into the mouth against the internal surface of the cheek and the sensor was positioned against the external surface of the cheek. The emitter was set at $13.5 \mathrm{~W}$ and activated for 5 seconds with a pulse setting of $10 \mathrm{~Hz}$. The protocol was repeated three times. Human structures which were thinner than $9 \mathrm{~mm}$ were also measured in an identical fashion, including the web of the human hand $(7 \mathrm{~mm})$ and the human ear $(5 \mathrm{~mm})$. The latter structure allowed measurement of NIR penetration through anatomical structures of skin, cartilage, connective tissue, and blood. These measurements were replicated three times.

\section{Penetration in human tissue}

In vivo human tissue studies were conducted to assess the impact of blood flow and the absence of postmortem protein cross-linking and other possible changes to the manner in which NIR penetrated tissue. Several different tissues were examined (Table 4). Only the $810 \mathrm{~nm}$ laser at an output setting of $13.5 \mathrm{~W}$ was utilized in this portion of the study. All reported values were statistically different from transmission through an equal distance of air. Pulsed NIR appeared to have greater penetration in living tissue, unlike the finding in postmortem tissue. Only $0.6 \%$ of continuous wave NIR energy passed through $2.5-3.0 \mathrm{~cm}$ of human hand, while $0.8 \%$ of pulsed NIR penetrated the same distance. Penetration also appeared to be greater in living tissues that contained bone (human hand) compared to a similar thickness of subcutaneous flesh. Over $0.8 \%$ of the NIR energy passed through $25 \mathrm{~mm}$ of human hand, while only $0.3 \%$ of NIR penetrated a similar depth of tissue with no bones (subcutaneous flesh). Also, cartilage (ear) appeared to allow greater energy transmission compared to a similar thickness 

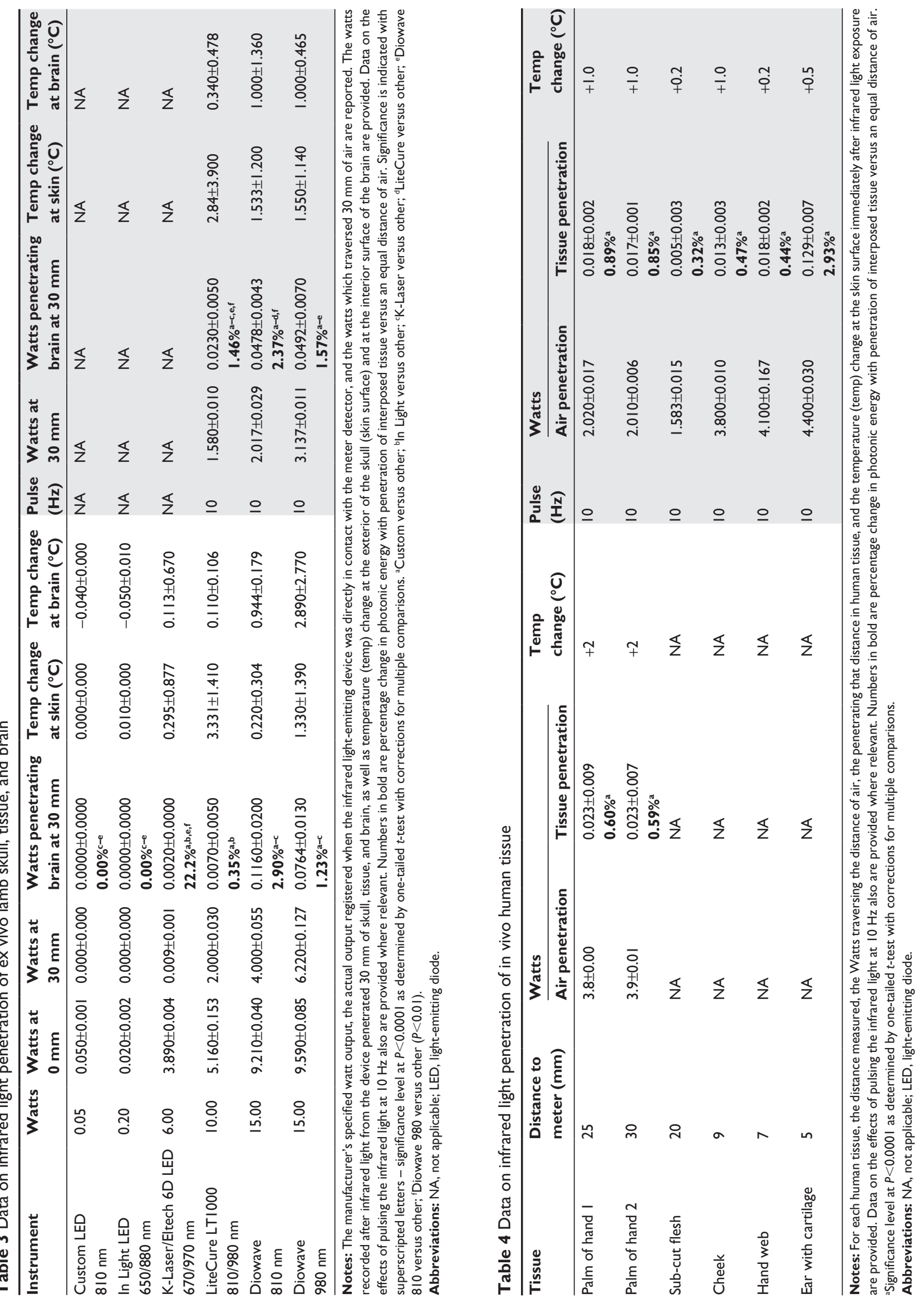
of skin (hand web). Temperature change after 5 seconds was $2{ }^{\circ} \mathrm{C}$ or less at the skin surface and dropped quickly possibly related to blood flow.

\section{Attenuation of NIR energy}

Given the much greater distance involved in delivering NIR in effective doses to the human brain, we examined NIR penetration to $3 \mathrm{~cm}$ depth through the skin, skull, and brain of ex vivo sheep head. As could be anticipated from the penetration studies of skin, the low power NIR emitters showed no evidence of penetration to this depth. The $6 \mathrm{~W}$ NIR emitter transmitted less than $1 / 10$ of $1 \%$ of its surface energy through $3 \mathrm{~cm}$ of skull and brain. It did demonstrate that red light $(670 \mathrm{~nm})$ transmitted better $-22 \%$ of the red light energy that traversed $3 \mathrm{~cm}$ of air was able to penetrate $3 \mathrm{~cm}$ of tissue. High-powered NIR lasers delivered between $0.5 \%$ and $3.0 \%$ of their energy to the depth of the brain. Notably, penetration to this depth was significantly better using $810 \mathrm{~nm}$ NIR than it was when using $980 \mathrm{~nm}$ NIR. This is advantageous given the stronger evidence of $810 \mathrm{~nm}$ light being effective in photomodulation of neurological function. . $^{87,88,91-94}$

These tissue studies indicate NIR energy penetrates to depths of $3 \mathrm{~cm}$ whether in ex vivo or living tissue; however, sufficient energy must be delivered to the skin surface. The 0.2 and $0.5 \mathrm{~W}$ NIR diodes yielded no detectable energy at $3 \mathrm{~cm}$ depth. High-powered NIR lasers were able to deliver between $0.5 \%$ and $3.0 \%$ of their energy to the depth of $3 \mathrm{~cm}$ in living or postmortem tissue, with living tissue absorbing more energy over the intervening distance. Based on the power density of $55-81 \mathrm{~J} / \mathrm{cm}^{2}$ delivered to the skin of patients in our clinical cases ${ }^{3,118}$ (using a 10-15 W NIR, $810 / 980 \mathrm{~nm}$, or $810 \mathrm{~nm}$ laser), then the expected power density in the human brain at $3 \mathrm{~cm}$ depth would be in the range of $0.8-2.4 \mathrm{~J} / \mathrm{cm}^{2}-$ precisely in the range shown to induce neurological benefit in animal models. ${ }^{4,81,87,88,92-94}$ The safety of NIR exposure at high doses has been explored in animal models ${ }^{119-121}$ and in humans. ${ }^{3,55,115}$

\section{Putting penetration in perspective}

One of the earliest studies of NIR penetration and human skin examined transmittance of $633 \mathrm{~nm}$ light through progressively thicker sections of human skin. ${ }^{102}$ Penetration through $0.4 \mathrm{~mm}$ of epidermis was $78 \%$ for $633 \mathrm{~nm}$ light and at $2 \mathrm{~mm}$, the energy had dropped to approximately $5 \%$ of the incident $633 \mathrm{~nm}$ light. Later, the same group found no penetration of infrared light beyond $3 \mathrm{~mm}$ using the same light sources. ${ }^{114}$ Bjordal et al ${ }^{8}$ also concluded that $90 \%$ of the energy from $632 \mathrm{~nm}$ laser is lost in the skin. NIR at $820 \mathrm{~nm}$ has slightly greater skin penetration. Approximately $89 \%$ of $820 \mathrm{~nm}$ light will penetrate $0.4 \mathrm{~mm}$ of epidermis and about $13.5 \%$ traverses $2 \mathrm{~mm}$ of skin, ${ }^{102}$ but $0 \%$ reaches a depth of $3 \mathrm{~mm} .{ }^{114}$ Others found $80 \%$ of the energy from an $820 \mathrm{~nm}$ source is lost in the skin. ${ }^{8}$ Human skin also was examined by Esnouf et a ${ }^{104}$ using an $850 \mathrm{~nm}$ continuous light source at $100 \mathrm{~mW}$. They reported $34 \%$ of the light from the source could penetrate $0.784 \mathrm{~mm} .{ }^{104}$ The $904 \mathrm{~nm}$ laser may have greater skin penetration. ${ }^{8}$ Using rat skin of an unspecified thickness, Joensen et al ${ }^{113}$ found $20 \%$ of the $810 \mathrm{~nm}$ light from a $200 \mathrm{~mW}$ source penetrated skin. Our results show considerably less penetration by low level NIR. We found energy from a $50 \mathrm{~mW} 810 \mathrm{~nm}$ LED did not penetrate $2 \mathrm{~mm}$ of human or sheep skin. No energy could be detected penetrating either human skin or sheep skin from a commercially available $0.2 \mathrm{~W}$ LED $(650+880 \mathrm{~nm})$. In contrast, $9 \%$ of the energy from the $10 \mathrm{~W}$ combined $810 / 980 \mathrm{~nm}$ continuous wave infrared laser passed through $2 \mathrm{~mm}$ of skin (human or sheep). The $15 \mathrm{~W} 810$ laser in continuous mode delivered $33 \%$ of its energy through $2 \mathrm{~mm}$ of skin. While longer wavelength is typically associated with greater penetration, we found that only $14 \%$ of the energy from a $15 \mathrm{~W} 980 \mathrm{~nm}$ laser in continuous mode penetrated $2 \mathrm{~mm}$ of (sheep) skin. These data are consistent with the transmission properties reported for skin, which has relatively good transmission in the range of $810 \mathrm{~nm}$ and somewhat less transmission at $980 \mathrm{~nm} .{ }^{122}$ Using pulsed infrared light yielded much greater penetration. For example, $41 \%$ of the power density of a combined 810/980 nm infrared laser with a pulse frequency of $10 \mathrm{~Hz}$ penetrated $1.9 \mathrm{~mm}$ of human skin compared to only $11 \%$ of the continuous wave light of similar parameters. The $15 \mathrm{~W} 810 \mathrm{~nm}$ laser with a pulse frequency of $10 \mathrm{~Hz}$ showed $69 \%$ of the energy penetrated $1.9 \mathrm{~mm}$ of human skin compared to only $17 \%$ of the continuous wave light of similar parameters.

Thicker segments of tissue have been studied by several groups. Penetration through mouse skull $(0.2 \mathrm{~mm})^{108}$ and overlying skin with $800-810 \mathrm{~nm}$ light from an LLLT emitter ranges from $6.3 \%{ }^{95}$ to $46 \% .{ }^{109}$ Penetration through the entire depth of a mouse brain $(3-5 \mathrm{~mm})$ is reportedly $1 \%-4 \% .{ }^{109}$ Byrnes et al ${ }^{122}$ examined penetration of $810 \mathrm{~nm}$ continuous light from a $150 \mathrm{~mW}$ source through skin, muscle, bone, and spinal cord of the rat $(\sim 24 \mathrm{~mm})$. They found $6 \%$ of the energy penetrated these tissues. Similarly, Giacci et al ${ }^{16}$ measured photonic energy transmission through an unspecified thickness of skin and muscle overlying the spinal column of the rat and found $6.6 \%$ of $670 \mathrm{~nm}$ light from a $0.5 \mathrm{~W}$ emitter penetrated this distance. Penetration of $830 \mathrm{~nm}$ light 
was slightly greater at $11.3 \% .{ }^{16}$ Penetration of these same wavelengths from the skin of the rat head to the optic nerve was estimated at $0.1 \% .{ }^{16}$ Hudson et al ${ }^{112}$ precisely measured photonic energy at varying depths of bovine muscle using a 1 W 808/980 nm emitter. They found $808 \mathrm{~nm}$ light had greater penetration, despite the premise that longer wavelengths travel further. Indeed, the attenuation of $808 \mathrm{~nm}$ light at $3 \mathrm{~cm}$ was $99 \%$, quite similar to the findings we describe here in both living human hand and the more heterogenous media of the ovine head.

In living human hand $(25 \mathrm{~mm})$, Jagdeo et $\mathrm{al}^{117}$ found only $0.01 \%-0.09 \%$ of $830 \mathrm{~nm}$ light from a $0.5 \mathrm{~W}$ emitter penetrated this distance. We found that $0.6 \%$ of $810 \mathrm{~nm}$ light from a higher-powered source $(10 \mathrm{~W})$ was able to penetrate $25 \mathrm{~mm}$ of skin, bone, and soft tissue. This represents at least a sixfold increase in penetration compared to previous work with low power emitters.

Fitzgerald et al ${ }^{111}$ modeled light penetration into the brain for a $670 \mathrm{~nm}$ and a 1,064 $\mathrm{nm}$ LED light source emitting $28 \mathrm{~mW} / \mathrm{cm}^{2}$. Using a diffusion simulation computer model with assumptions of $10 \mathrm{~mm}$ of overlying scalp and skull, they derived that $2.5 \mathrm{~mW} / \mathrm{cm}^{2}$ for $670 \mathrm{~nm}$ light and $13 \mathrm{~mW} /$ $\mathrm{cm}^{2}$ for 1,064 $\mathrm{nm}$ light would reach the surface of the cerebral cortex. ${ }^{111}$ They further derived that at the center of the brain $(10 \mathrm{~mm}$ skull $+46 \mathrm{~mm}$ brain $=56 \mathrm{~mm})$, power density would be approximately $1.2 \times 10^{-11} \mathrm{~W} / \mathrm{cm}^{2}$ for $670 \mathrm{~nm}$ light and $1.4 \times 10^{-7} \mathrm{~W} / \mathrm{cm}^{2}$ for 1,064 nm light. ${ }^{111}$

Jagdeo et al also examined LLLT penetration through isolated human skull from cadaver and found it was limited with only $7.4 \%$ of the light from an $830 \mathrm{~nm} 0.5 \mathrm{~W}$ continuous LED device (Omnilux) penetrating the bone. ${ }^{117}$ Moreover, they found that no more than $0.5 \%$ of NIR at $830 \mathrm{~nm}$ penetrated approximately $10 \mathrm{~mm}$ of frontal skull and overlying tissue in a cadaver model. Also, no detectable NIR penetrated the temporal bone and overlying tissue. ${ }^{117}$ These studies of LLLT and the computer model indicate that photonic energy from LLLT emitters does not appear to deliver significant fluence to the depths required to treat the human brain.

Our studies of $3 \mathrm{~cm}$ of sheep skull, brain, and overlying soft tissue are the closest model of the clinical practice of NILT for TBI. Again, NIR from devices generating less than $1 \mathrm{~W}$ could not be detected at this depth. The energy from a 6 W LED system showed a 99.995\% drop across $3 \mathrm{~cm}$ of tissue. In contrast, $0.14 \%$ of the energy from a $10 \mathrm{~W}$ $810 / 980 \mathrm{~nm}$ device penetrated $3 \mathrm{~cm}$ of tissue. At $15 \mathrm{~W}$, an $810 \mathrm{~nm}$ emitter in continuous mode delivered $1.26 \%$ of the surface power density and $0.80 \%$ of the $980 \mathrm{~nm}$ device emissions reached the $3 \mathrm{~cm}$ depth through brain tissue. Using pulsed NIR emission settings, a lower overall power density was delivered to the surface; however, similar penetration was achieved.

Some have suggested that NIR has a dosing window and have reported a bimodal response curve, such that high-dose NIR could be detrimental; 4,5 however, others have shown a dose-dependent response to NIR with no detrimental effects at higher doses. ${ }^{80}$

The penetration data mentioned and the data presented herein challenge the presumption that only LLLT protocols spanning weeks or months would possibly be clinically effective. For example, using a $0.5 \mathrm{~W} 830 \mathrm{~nm}$ LED, Jagdeo et $\mathrm{al}^{117}$ estimated the power density reaching the cerebral cortex based on their model was $3 \mathrm{~mW} / \mathrm{cm}^{2}$, which equates to a fluence of $0.0064 \mathrm{~J} / \mathrm{cm}^{2}-1 / 140$ th of the minimum thought to be necessary for ideal photobiomodulation. ${ }^{5}$ Anders and colleagues noted NIR penetrates $4 \mathrm{~cm}$ into human cadaver skin, skull, and brain using a $5 \mathrm{~W}$ laser (JJ Anders, personal communication, January 13, 2015). From our data, we estimate that in our clinical applications of high-powered NIR lasers, ${ }^{3}$ we are delivering $0.64-1.95 \mathrm{~J} / \mathrm{cm}^{2}$ to a depth of $30 \mathrm{~mm}$. This is 100-fold greater fluence than that delivered by an LED system, but within the range of fluence shown to have beneficial biological effects.

\section{Conclusion}

Extensive research has shown the fluence within the range of $0.9-15.0 \mathrm{~J} / \mathrm{cm}^{2}$ is most effective in activating the biological processes involved in reversing or mitigating the pathophysiological effects of TBI. The attenuation of NIR energy as it passes through tissue has been examined in computer simulations, animal tissue, and human tissue. NIR penetration in the human brain is subject to attenuation by multiple tissues (skin, skull, dura, blood, cerebrospinal fluid) and multiple interfaces which scatter, absorb, and reflect the NIR to varying degrees. We have shown through the use of higher wattage NIR lasers that we can deliver fluence at therapeutic levels to the depths of the brain without tissue heating or damage. The protocols have been applied in our clinic with excellent clinical results and no side effects.

\section{Acknowledgments}

The authors would like to acknowledge the technical assistance of Phillip Hardinger, DC, DABCO, and Mr Charles Vorwaller (Diowave Corporation/LiteCure Corporation). Artistic creation Figure 1: Ms Taylor Tuteur. 


\section{Disclosure}

Dr Larry Morries is CEO of the Neuro-Laser Foundation, a nonprofit foundation. He has a private practice in Lakewood, CO, USA.

Theodore A Henderson is president of The Synaptic Space, a medical consulting firm and president of Dr Theodore Henderson, Inc, a clinical service firm. He is also co-owner of Neuro-Luminance, a clinical service organization, president of the International Society of Applied Neuroimaging, and CFO of the Neuro-Laser Foundation.

\section{References}

1. Hyder AA, Wunderlich CA, Puvanachandra P, Gururaj G, Kobusingye OC. The impact of traumatic brain injuries: a global perspective. Neuro Rehabilitation. 2007;22(5):341-353.

2. Feigin VL, Forouzanfar MH, Krishnamurthi R, et al; Global Burden of Diseases, Injuries, and Risk Factors Study 2010 (GBD 2010), GBD Stroke Experts Group. Global and regional burden of stroke during 1990-2010: findings from the Global Burden of Disease Study 2010 Lancet. 2014;383(9913):245-254.

3. Morries LD, Cassano P, Henderson TA. Treatments for traumatic brain injury with emphasis on transcranial near infrared laser phototherapy. Neuropsychiatr Dis Treat. In press 2015.

4. Chung H, Dai T, Sharma SK, Huang YY, Carroll JD, Hamblin MR. The nuts and bolts of low-level laser (light) therapy. Ann Biomed Eng 2012;40(2):516-533.

5. Huang YY, Chen AC, Carroll JD, Hamblin MR. Biphasic dose response in low level light therapy. Dose Response. 2009;7(4):358-383.

6. Enwemeka CS. Intricacies of dose in laser phototherapy for tissue repair and pain relief. Photomed Laser Surg. 2009;27(3):387-393.

7. Mester E, Mester AF, Mester A. The biomedical effects of laser application. Lasers Surg Med. 1985;5(1):31-39.

8. Bjordal JM, Couppé C, Chow RT, Tunér J, Ljunggren EA. A systematic review of low level laser therapy with location-specific doses for pain from chronic joint disorders. Aust J Physiother. 2003;49(2): 107-116.

9. Basford JR, Sheffield CG, Harmsen WS. Laser therapy: a randomized, controlled trial of the effects of low-intensity Nd:YAG laser irradiation on musculoskeletal back pain. Arch Phys Med Rehabil. 1999; 80(6):647-652.

10. Yang Z, Wu Y, Zhang $\mathrm{H}$, et al. Low-level laser irradiation alters cardiac cytokine expression following acute myocardial infarction: a potential mechanism for laser therapy. Photomed Laser Surg. 2011; 29(6):391-398.

11. Tuby H, Maltz L, Oron U. Induction of autologous mesenchymal stem cells in the bone marrow by low-level laser therapy has profound beneficial effects on the infarcted rat heart. Lasers Surg Med. 2011; 43(5):401-409.

12. Lapchak PA. Taking a light approach to treating acute ischemic stroke patients: transcranial near-infrared laser therapy translational science. Ann Med. 2010;42(8):576-586.

13. Lampl Y, Zivin JA, Fisher M, et al. Infrared laser therapy for ischemic stroke: a new treatment strategy: results of the NeuroThera Effectiveness and Safety Trial-1 (NEST-1). Stroke. 2007;38(6):1843-1849.

14. Hacke W, Schellinger PD, Albers GW, et al; NEST 3 Committees and Investigators. Transcranial laser therapy in acute stroke treatment: results of neurothera effectiveness and safety trial 3, a phase III clinical end point device trial. Stroke. 2014;45(11):3187-3193.

15. Lavery LA, Murdoch DP, Williams J, Lavery DC. Does anodyne light therapy improve peripheral neuropathy in diabetes? A double-blind, sham-controlled, randomized trial to evaluate monochromatic infrared photoenergy. Diabetes Care. 2008;31(2):316-321.
16. Giacci MK, Wheeler L, Lovett S, et al. Differential effects of 670 and $830 \mathrm{~nm}$ red near infrared irradiation therapy: a comparative study of optic nerve injury, retinal degeneration, traumatic brain and spinal cord injury. PLoS One. 2014;9(8):e104565.

17. Veech RL, Valeri CR, VanItallie TB. The mitochondrial permeability transition pore provides a key to the diagnosis and treatment of traumatic brain injury. IUBMB Life. 2012;64(2):203-207.

18. Barkhoudarian G, Hovda DA, Giza CC. The molecular pathophysiology of concussive brain injury. Clin Sports Med. 2011;30(1):33-48.

19. Prins M, Greco T, Alexander D, Giza CC. The pathophysiology of traumatic brain injury at a glance. Dis Model Mech. 2013;6(6): 1307-1315.

20. Cheng G, Kong RH, Zhang LM, Zhang JN. Mitochondria in traumatic brain injury and mitochondrial-targeted multipotential therapeutic strategies. Br J Pharmacol. 2012;167(4):699-719.

21. Xiong Y, Gu Q, Peterson PL, Muizelaar JP, Lee CP. Mitochondrial dysfunction and calcium perturbation induced by traumatic brain injury. J Neurotrauma. 1997;14(1):23-34.

22. Lifshitz J, Friberg H, Neumar RW, et al. Structural and functional damage sustained by mitochondria after traumatic brain injury in the rat: evidence for differentially sensitive populations in the cortex and hippocampus. J Cereb Blood Flow Metab. 2003;23(2):219-231.

23. Lifshitz J, Sullivan PG, Hovda DA, Wieloch T, McIntosh TK. Mitochondrial damage and dysfunction in traumatic brain injury. Mitochondrion . 2004;4(5-6):705-713

24. Pandya JD, Nukala VN, Sullivan PG. Concentration dependent effect of calcium on brain mitochondrial bioenergetics and oxidative stress parameters. Front Neuroenergetics. 2013;18(5):10.

25. Violi F, Marino R, Milite MT, Loffredo L. Nitric oxide and its role in lipid peroxidation. Diabetes Metab Res Rev. 1999;15(4):283-288.

26. Singh IN, Sullivan PG, Hall ED. Peroxynitrite-mediated oxidative damage to brain mitochondria: Protective effects of peroxynitrite scavengers. J Neurosci Res. 2007;85(10):2216-2223.

27. Mustafa AG, Singh IN, Wang J, Carrico KM, Hall ED. Mitochondrial protection after traumatic brain injury by scavenging lipid peroxyl radicals. J Neurochem. 2010;114(1):271-280.

28. Sharma P, Su YA, Barry ES, Grunberg NE, Lei Z. Mitochondrial targeted neuron focused genes in hippocampus of rats with traumatic brain injury. Int J Crit Illn Inj Sci. 2012;2(3):172-179.

29. Ip EY, Zanier ER, Moore AH, Lee SM, Hovda DA. Metabolic, neurochemical, and histologic responses to vibrissa motor cortex stimulation after traumatic brain injury. J Cereb Blood Flow Metab. 2003; 23(8):900-910.

30. Hattori N, Huang SC, Wu HM, et al. Acute changes in regional cerebral (18)F-FDG kinetics in patients with traumatic brain injury. J Nucl Med. 2004;45(5):775-783.

31. Byrnes KR, Wilson CM, Brabazon F, et al. FDG-PET imaging in mild traumatic brain injury: a critical review. Front Neuroenergetics. 2014;5:13.

32. Raji CA, Tarzwell R, Pavel D, et al. Clinical utility of SPECT neuroimaging in the diagnosis and treatment of traumatic brain injury: a systematic review. PLoS One. 2014;9(3):e91088.

33. Liu YR, Cardamone L, Hogan RE, et al. Progressive metabolic and structural cerebral perturbations after traumatic brain injury: an in vivo imaging study in the rat. J Nucl Med. 2010;51(11):1788-1795.

34. Toklu HZ, Hakan T, Biber N, Solakoğlu S, Oğünç AV, Sener G. The protective effect of alpha lipoic acid against traumatic brain injury in rats. Free Radic Res. 2009;43(7):658-667.

35. Cornelius C, Crupi R, Calabrese V, et al. Traumatic brain injury: oxidative stress and neuroprotection. Antioxid Redox Signal. 2013;19(8): 836-853.

36. Ziebell JM, Morganti-Kossmann MC. Involvement of pro- and antiinflammatory cytokines and chemokines in the pathophysiology of traumatic brain injury. Neurotherapeutics. 2010;7(1):22-30.

37. Kumar A, Loane DJ. Neuroinflammation after traumatic brain injury: opportunities for therapeutic intervention. Brain Behav Immun. 2012; 26(8):1191-1201 
38. Finnie JW. Neuroinflammation: beneficial and detrimental effects after traumatic brain injury. Inflammopharmacology. 2013;21(4):309-320.

39. Ramlackhansingh AF, Brooks DJ, Greenwood RJ, et al. Inflammation after trauma: microglial activation and traumatic brain injury. Ann Neurol. 2011;70(3):374-383.

40. Hall ED, Bryant YD, Cho W, Sullivan PG. Evolution of post-traumatic neurodegeneration after controlled cortical impact traumatic brain injury in mice and rats as assessed by the de Olmos silver and fluorojade staining methods. J Neurotrauma. 2008;25(3):235-247.

41. Metting Z, Cerliani L, Rödiger LA, van der Naalt J. Pathophysiological concepts in mild traumatic brain injury: diffusion tensor imaging related to acute perfusion CT imaging. PLoS One. 2013;8(5):e64461.

42. Leker RR, Shohami E. Cerebral ischemia and trauma - different etiologies yet similar mechanisms: neuroprotective opportunities. Brain Res Brain Res Rev. 2002;39(1):55-73.

43. Naviaux RK. Metabolic features of the cell danger response. Mitochondrion. 2014;16:7-17.

44. Lin AP, Liao HJ, Merugumala SK, Prabhu SP, Meehan WP 3rd, Ross BD. Metabolic imaging of mild traumatic brain injury. Brain Imaging Behav. 2012;6(2):208-223.

45. Boussi-Gross R, Golan H, Fishlev G, et al. Hyperbaric oxygen therapy can improve post concussion syndrome years after mild traumatic brain injury - randomized prospective trial. PLoS One. 2013;8(11):e79995.

46. DeKosky ST, Blennow K, Ikonomovic MD, Gandy S. Acute and chronic traumatic encephalopathies: pathogenesis and biomarkers. Nat Rev Neurol. 2013;9(4):192-200.

47. Lye TC, Shores EA. Traumatic brain injury as a risk factor for Alzheimer's disease: a review. Neuropsychol Rev. 2000;10(2):115-129.

48. Sundman MH, Hall EE, Chen NK. Examining the relationship between head trauma and neurodegenerative disease: A review of epidemiology, pathology and neuroimaging techniques. J Alzheimers Dis Parkinsonism. 2014;4. pii: 137.

49. McKee AC, Cantu RC, Nowinski CJ, et al. Chronic traumatic encephalopathy in athletes: progressive tauopathy after repetitive head injury. J Neuropathol Exp Neurol. 2009;68(7):709-735.

50. Hutson CB, Lazo CR, Mortazavi F, Giza CC, Hovda D, Chesselet MF. Traumatic brain injury in adult rats causes progressive nigrostriatal dopaminergic cell loss and enhanced vulnerability to the pesticide paraquat. J Neurotrauma. 2011;28(9):1783-1801.

51. Wong JC, Hazrati LN. Parkinson's disease, parkinsonism, and traumatic brain injury. Crit Rev Clin Lab Sci. 2013;50(4-5):103-106.

52. Ryu J, Horkayne-Szakaly I, Xu L, et al. The problem of axonal injury in the brains of veterans with histories of blast exposure. Acta Neuropathol Commun. 2014;2(1):153.

53. Mochizuki-Oda N, Kataoka Y, Cui Y, Yamada H, Heya M, Awazu K. Effects of near-infra-red laser irradiation on adenosine triphosphate and adenosine diphosphate contents of rat brain tissue. Neurosci Lett. 2002;323(3):207-210.

54. Rojas JC, Gonzalez-Lima F. Low level light therapy of the eye and brain. Eye Brain. 2011;3:49-67.

55. Lapchak PA, Wei J, Zivin JA. Transcranial infrared laser therapy improves clinical rating scores after embolic strokes in rabbits. Stroke. 2004;35(8):1985-1988.

56. Karu TI, Kolyakov SF. Exact action spectra for cellular responses relevant to phototherapy. Photomed Laser Surg. 2005;23(4):355-361.

57. Wong-Riley MT, Liang HL, Eells JT, et al. Photobiomodulation directly benefits primary neurons functionally inactivated by toxins: role of cytochrome c oxidase. J Biol Chem. 2005;280(6):4761-4771.

58. Passarella S. He-Ne laser irradiation of isolated mitochondria. J Photochem Photobiol B. 1989;3(4):642-643.

59. Pastore D, Greco M, Passarella S. Specific helium-neon laser sensitivity of the purified cytochrome c oxidase. Int J Radiat Biol. 2000;76(6): 863-870.

60. Yu W, Naim JO, McGowan M, Ippolito K, Lanzafame RJ. Photomodulation of oxidative metabolism and electron chain enzymes in rat liver mitochondria. Photochem Photobiol. 1997;66(6):866-871.
61. Karu TI, Piatibrat LV, Tiflova OA, Nikogosian DN. [Specificity of the lethal and mutagenic actions of pico-second laser pulses of 532-nm wavelength.] Radiobiologiia. 1988;28(4):499-502. Russian.

62. Karu TI. Mitochondrial signaling in mammalian cells activated by red and near-IR radiation. Photochem Photobiol. 2008;84(5): 1091-1099.

63. Fujimaki Y, Shimoyama T, Liu Q, Umeda T, Nakaji S, Sugawara K. Low-level laser irradiation attenuates production of reactive oxygen species by human neutrophils. J Clin Laser Med Surg. 2003;21(3): 165-170.

64. Liang HL, Whelan HT, Eells JT, Wong-Riley MT. Near-infrared light via light-emitting diode treatment is therapeutic against rotenone- and 1-methyl-4-phenylpyridinium ion-induced neurotoxicity. Neuroscience. 2008;153(4):963-974.

65. Muili KA, Gopalakrishnan S, Eells JT, Lyons JA. Photobiomodulation induced by $670 \mathrm{~nm}$ light ameliorates MOG35-55 induced EAE in female C57BL/6 mice: a role for remediation of nitrosative stress. PLoS One. 2013;8(6):e67358.

66. Karu TI. Cellular mechanism of low power laser therapy: new questions. In: Simunovic F, editor. Lasers in Medicine and Dentistry. Vol 3. Rijeka: Z Vitgraf; 2003:79-100.

67. Kobari M, Fukuuchi Y, Tomita M, Tanahashi N, Takeda H. Role of nitric oxide in regulation of cerebral microvascular tone and autoregulation of cerebral blood flow in cats. Brain Res. 1994;667(2):255-262.

68. Leung MC, Lo SC, Siu FK, So KF. Treatment of experimentally induced transient cerebral ischemia with low energy laser inhibits nitric oxide synthase activity and up-regulates the expression of transforming growth factor-beta 1. Lasers Surg Med. 2002;31(4):283-288.

69. Brondon P, Stadler I, Lanzafame RJ. A study of the effects of phototherapy dose interval on photobiomodulation of cell cultures. Lasers Surg Med. 2005;36(5):409-413.

70. Moriyama Y, Moriyama EH, Blackmore K, Akens MK, Lilge L. In vivo study of the inflammatory modulating effects of low-level laser therapy on iNOS expression using bioluminescence imaging. Photochem Photobiol. 2005;81(6):1351-1355.

71. D'Angio CT, Finkelstein JN. Oxygen regulation of gene expression: a study in opposites. Mol Genet Metab. 2000;71(1-2):371-380.

72. Chen AC, Arany PR, Huang YY, et al. Low-level laser therapy activates $\mathrm{NF}-\mathrm{kB}$ via generation of reactive oxygen species in mouse embryonic fibroblasts. PLoS One. 2011;6(7):e22453.

73. Häcker H, Karin M. Regulation and function of IKK and IKK-related kinases. Sci STKE. 2006;2006(357):re13.

74. Vacca RA, Marra E, Quagliariello E, Greco M. Activation of mitochondrial DNA replication by He-Ne laser irradiation. Biochem Biophys Res Commun. 1993;195(2):704-709.

75. Greco M, Vacca RA, Moro L, et al. Helium-Neon laser irradiation of hepatocytes can trigger increase of the mitochondrial membrane potential and can stimulate c-fos expression in a $\mathrm{Ca} 2+-$ dependent manner. Lasers Surg Med. 2001;29(5):433-441.

76. Kushibiki T, Hirasawa T, Okawa S, Ishihara M. Regulation of miRNA Expression by Low-Level Laser Therapy (LLLT) and Photodynamic Therapy (PDT). Int J Mol Sci. 2013;14(7):13542-13558.

77. Zhang Y, Song S, Fong CC, Tsang CH, Yang Z, Yang M. cDNA microarray analysis of gene expression profiles in human fibroblast cells irradiated with red light. J Invest Dermatol. 2003;120(5):849-857.

78. Eells JT, Wong-Riley MT, VerHoeve J, et al. Mitochondrial signal transduction in accelerated wound and retinal healing by near-infrared light therapy. Mitochondrion. 2004;4(5-6):559-567.

79. Szymanska J, Goralczyk K, Klawe JJ, et al. Phototherapy with lowlevel laser influences the proliferation of endothelial cells and vascular endothelial growth factor and transforming growth factor-beta secretion. J Physiol Pharmacol. 2013;64(3):387-391.

80. von Leden RE, Cooney SJ, Ferrara TM, et al. $808 \mathrm{~nm}$ wavelength light induces a dose-dependent alteration in microglial polarization and resultant microglial induced neurite growth. Lasers Surg Med. 2013; 45(4):253-263 
81. Xuan W, Agrawal T, Huang L, Gupta GK, Hamblin MR. Low-level laser therapy for traumatic brain injury in mice increases brain derived neurotrophic factor (BDNF) and synaptogenesis. J Biophotonics. 2014;8(6):502-511.

82. Frank S, Oliver L, Lebreton-De Coster C, et al. Infrared radiation affects the mitochondrial pathway of apoptosis in human fibroblasts. J Invest Dermatol. 2004;123(5):823-831.

83. Lubart R, Eichler M, Lavi R, Friedman H, Shainberg A. Low-energy laser irradiation promotes cellular redox activity. Photomed Laser Surg. 2005;23(1):3-9.

84. Mirsky N, Krispel Y, Shoshany Y, Maltz L, Oron U. Promotion of angiogenesis by low energy laser irradiation. Antioxid Redox Signal. 2002;4(5):785-790.

85. Schwartz F, Brodie C, Appel E, Kazimirsky G, Shainberg A. Effect of helium/neon laser irradiation on nerve growth factor synthesis and secretion in skeletal muscle cultures. J Photochem Photobiol B. 2002;66(3):195-200.

86. Meng C, He Z, Xing D. Low-level laser therapy rescues dendrite atrophy via upregulating BDNF expression: implications for Alzheimer's disease. J Neurosci. 2013;33(33):13505-13517.

87. Oron A, Oron U, Streeter J, et al. Low-level laser therapy applied transcranially to mice following traumatic brain injury significantly reduces long-term neurological deficits. J Neurotrauma. 2007;24(4): 651-656.

88. Oron A, Oron U, Chen J, et al. Low level laser therapy applied transcranially to rats after induction of stroke significantly reduces long-term neurological deficits. Stroke. 2006;37(10):2620-2624.

89. Lapchak PA. Transcranial near-infrared laser therapy applied to promote clinical recovery in acute and chronic neurodegenerative diseases. Expert Rev Med Devices. 2012;9(1):71-83.

90. Yip KK, Lo SC, Leung MC, So SK, Tang CY, Poon DM. The effect of low-energy laser irradiation on apoptotic factors following experimentally induced transient cerebral ischemia. Neuroscience. 2011;190:301-306

91. Wu HM, Huang SC, Vespa P, Hovda DA, Bergsneider M. Redefining the pericontusional penumbra following traumatic brain injury: evidence of deteriorating metabolic derangements based on positron emission tomography. J Neurotrauma. 2013;30(5):352-360.

92. Xuan W, Vatansever F, Huang L, et al. Transcranial low-level laser therapy improves neurological performance in traumatic brain injury in mice: effect of treatment repetition regimen. PLoS One. 2013;8(1):e53454.

93. Wu Q, Xuan W, Ando T, et al. Low-level laser therapy for closed-head traumatic brain injury in mice: effect of different wavelengths. Lasers Surg Med. 2012;44(3):218-226.

94. Ando T, Xuan W, Xu T, et al. Comparison of therapeutic effects between pulsed and continuous wave $810-\mathrm{nm}$ wavelength laser irradiation for traumatic brain injury in mice. PLoS One. 2011;6(10): e26212.

95. Jenkins PA, Carroll JD. How to report low-level laser therapy (LLLT) photomedicine dose and beam parameters in clinical and laboratory studies. Photomed Laser Surg. 2011;29(12):785-787.

96. Steiner R. Laser-tissue interactions. In: Raulin C, Karsai S, editors. Laser and IPL Technology in Dermatology and Aesthetic Medicine. Berlin and Heidelberg: Springer-Verlag; 2011:23-36.

97. Lister T, Wright PA, Chappell PH. Optical properties of human skin. J Biomed Opt. 2012;17(9):090901.

98. Wan S, Parrish JA, Anderson RR, Madden M. Transmittance of nonionizing radiation in human tissues. Photochem Photobiol. 1981;34(6): 679-681.

99. Hode L. The importance of the coherency. Photomed Laser Surg. 2005;23(4):431-434.

100. Naeser MA, Saltmarche A, Krengel MA, Hamblin MR, Knight JA. Improved cognitive function after transcranial, light-emitting diode treatments in chronic, traumatic brain injury: two case reports. Photomed Laser Surg. 2011;29(5):351-358.
101. Nawashiro H, Wada K, Nakai K, Sato S. Focal increase in cerebral blood flow after treatment with near-infrared light to the forehead in a patient in a persistent vegetative state. Photomed Laser Surg. 2012;30(4):231-233.

102. Kolari PJ. Penetration of unfocused laser light into the skin. Arch Dermatol Res. 1985;277(4):342-344.

103. Franzen-Korzendorfer H, Blackinton M, Rone-Adams S, McCulloch J. The effect of monochromatic infrared energy on transcutaneous oxygen measurements and protective sensation: results of a controlled, double-blind, randomized clinical study. Ostomy Wound Manage. 2008;54(6):16-31.

104. Esnouf A, Wright PA, Moore JC, Ahmed S. Depth of penetration of an $850 \mathrm{~nm}$ wavelength low level laser in human skin. Acupunct Electrother Res. 2007;32(1-2):81-86.

105. Bashkatov AN, Genina EA, Kochubey VI, Tuchin VV. Optical properties of human skin, subcutaneous and mucous tissues in the wavelength range from 400 to 2,000 nm. J Phys D Appl Phys. 2005;38(15): 2543-2555.

106. Zivin JA, Albers GW, Bornstein N, et al; NeuroThera Effectiveness and Safety Trial-2 Investigators. Effectiveness and safety of transcranial laser therapy for acute ischemic stroke. Stroke. 2009; 40(4):1359-1364.

107. Stemer AB, Huisa BN, Zivin JA. The evolution of transcranial laser therapy for acute ischemic stroke, including a pooled analysis of NEST-1 and NEST-2. Curr Cardiol Rep. 2010;12(1):29-33.

108. Choi JJ, Pernot M, Brown TR, Small SA, Konofagou EE. Spatiotemporal analysis of molecular delivery through the blood-brain barrier using focused ultrasound. Phys Med Biol. 2007;52(18): $5509-5530$.

109. Khuman J, Zhang J, Park J, Carroll JD, Donahue C, Whalen MJ. Low-level laser light therapy improves cognitive deficits and inhibits microglial activation after controlled cortical impact in mice. $J \mathrm{Neu}$ rotrauma. 2012;29(2):408-417.

110. Anderson RR, Parrish JA. The optics of human skin. J Invest Dermatol. 1981;77(1):13-19.

111. Fitzgerald M, Hodgetts S, Van Den Heuvel C, et al. Red/near-infrared irradiation therapy for treatment of central nervous system injuries and disorders. Rev Neurosci. 2013;24(2):205-226.

112. Hudson DE, Hudson DO, Wininger JM, Richardson BD. Penetration of Laser Light at $808 \mathrm{~nm}$ and $980 \mathrm{~nm}$ in Bovine Tissue Samples. Photomed Laser Surg. 2013;31(4):163-168.

113. Joensen J, Ovsthus K, Reed RK, et al. Skin penetration time-profiles for continuous $810 \mathrm{~nm}$ and Superpulsed $904 \mathrm{~nm}$ lasers in a rat model. Photomed Laser Surg. 2012;30(12):688-694.

114. Kolari PJ, Airaksinen O. Poor penetration of infra-red and helium neon low power laser light into the dermal tissue. Acupunct Electrother Res. 1993;18(1):17-21.

115. Huisa BN, Stemer AB, Walker MG, Rapp K, Meyer BC, Zivin JA; NEST-1 and -2 investigators. Transcranial laser therapy for acute ischemic stroke: a pooled analysis of NEST-1 and NEST-2. Int J Stroke. 2013;8(5):315-320.

116. Samoilova KA, Bogacheva ON, Obolenskaya KD, Blinova MI, Kalmykova NV, Kuzminikh EV. Enhancement of the blood growth promoting activity after exposure of volunteers to visible and infrared polarized light. Part I: stimulation of human keratinocyte proliferation in vitro. Photochem Photobiol Sci. 2004;3(1):96-101.

117. Jagdeo JR, Adams LE, Brody NI, Siegel DM. Transcranial red and near infrared light transmission in a cadaveric model. PLoS One. 2012; 7(10): 47460.

118. Henderson TA, Morries LD. SPECT perfusion imaging demonstrates improvement of TBI with transcranial near infrared laser phototherapy. Adv Mind Body Med. In press 2015.

119. Lapchak PA, Han MK, Salgado KF, Streeter J, Zivin JA. Safety profile of transcranial near-infrared laser therapy administered in combination with thrombolytic therapy to embolized rabbits. Stroke. 2008;39(11):3073-3078. 
120. Ilic S, Leichliter S, Streeter J, Oron A, DeTaboada L, Oron U. Effects of power densities, continuous and pulse frequencies, and number of sessions of low-level laser therapy on intact rat brain. Photomed Laser Surg. 2006;24(4):458-466.

121. McCarthy TJ, De Taboada L, Hildebrandt PK, Ziemer EL, Richieri SP, Streeter J. Long-term safety of single and multiple infrared transcranial laser treatments in Sprague-Dawley rats. Photomed Laser Surg. 2010;28(5):663-667.
122. Byrnes KR, Waynant RW, Ilev IK, et al. Light promotes regeneration and functional recovery and alters the immune response after spinal cord injury. Lasers Surg Med. 2005;36(3):171-185.

\section{Publish your work in this journal}

Neuropsychiatric Disease and Treatment is an international, peerreviewed journal of clinical therapeutics and pharmacology focusing on concise rapid reporting of clinical or pre-clinical studies on a range of neuropsychiatric and neurological disorders. This journal is indexed on PubMed Central, the 'PsycINFO' database and CAS, and is the official journal of The International Neuropsychiatric Association (INA). The manuscript management system is completely online and includes a very quick and fair peer-review system, which is all easy to use. Visit http://www.dovepress.com/testimonials.php to read real quotes from published authors. 